\section{DiÁNOIA}

Diánoia

ISSN: 0185-2450

dianoia@filosoficas.unam.mx

Universidad Nacional Autónoma de México

México

GÓMEZ-TORRENTE, MARIO

El Wittgenstein de Kripke y la analogía entre reglas y fundamentos

Diánoia, vol. L, núm. 55, noviembre, 2005, pp. 55-94

Universidad Nacional Autónoma de México

Distrito Federal, México

Disponible en: http://www.redalyc.org/articulo.oa? $\mathrm{id}=58433519003$

- Cómo citar el artículo

- Número completo

- Más información del artículo

- Página de la revista en redalyc.org

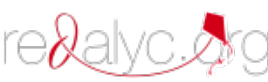

Sistema de Información Científica

Red de Revistas Científicas de América Latina, el Caribe, España y Portugal

Proyecto académico sin fines de lucro, desarrollado bajo la iniciativa de acceso abierto 


\title{
El Wittgenstein de Kripke y la analogía entre reglas y fundamentos*
}

\author{
MARIO GÓMEZ-TORRENTE \\ Instituto de Investigaciones Filosóficas \\ Universidad Nacional Autónoma de México \\ mariogt@servidor.unam.mx
}

\begin{abstract}
Resumen: Exploro un argumento en defensa del antifactualismo epistémico, la tesis de que las atribuciones epistémicas no describen hechos. El argumento es análogo a, pero independiente de, el argumento del Wittgenstein de Kripke en defensa del antifactualismo acerca de las atribuciones de seguir una regla. Considero y rechazo varias objeciones a los dos argumentos, en particular las acusaciones de incoherencia y "reductivismo". Sostengo que el argumento epistémico y una "solución escéptica" suya son parte de la concepción de Wittgenstein en Sobre la certeza.

Palabras clave: conocimiento, significado, escepticismo, antifactualismo
\end{abstract}

\begin{abstract}
I explore an argument for epistemic non-factualism, the thesis that epistemic attributions do not describe facts. The argument is analogous to but independent of Kripke's Wittgenstein's argument for non-factualism about rule-following. Some objections to the two arguments are considered and rejected, in particular accusations of incoherence and "reductivism". The epistemic argument and a "skeptical solution" to it are argued to be part of Wittgenstein's conception in On Certainty.

Key words: knowledge, meaning, skepticism, non-factualism
\end{abstract}

El objeto de este trabajo es explorar varias analogías profundas entre la noción de seguir una regla y la noción de tener un fundamento epistémico. Más específicamente, las analogías en cuestión son analogías entre las ideas antifactualistas que Kripke detecta en Wittgenstein y ciertas ideas antifactualistas acerca de las atribuciones epistémicas. Como es sabido, Kripke (1982) presenta un argumento inspirado en las secciones centrales de las Investigaciones filosóficas de Wittgenstein, un argumento cuya

* Partes de este trabajo han sido presentadas en el XVIII Simposio Internacional de Filosofía del Instituto de Investigaciones Filosóficas (México, 2000), en el II Taller "Language, Mind and World" (Tlaxcala, 2001), en el IV Congreso Europeo de Filosofía Analítica (Lund, 2002), en el IX Coloquio Iberoamericano de Filosofía (Río de Janeiro, 2004), en la Reunión de la División Este de la American Philosophical Association (Boston, 2004), y en conferencias en la Universidad de Barcelona (2002), la Universidad Libre de Berlín (2002), la Universidad Autónoma de Madrid (2003) y la Universidad de Santiago de Compostela (2004). Agradezco sus comentarios a los auditorios de estas pláticas y a dos dictaminadores anónimos de Diánoia. Doy también las gracias a Pedro Stepanenko por su estímulo y su interés en ver publicadas estas ideas. Como menciono en el texto, el trabajo, a pesar de su extensión, contiene sólo una presentación relativamente breve e introductoria de los temas tratados, sin pretensiones de exhaustividad. Creo que una presentación publicada de este tipo puede ser ya de alguna utilidad, mientras que la preparación de una presentación más extensa, quizá en forma de libro, habría postergado indefinidamente la publicación. Espero tener posteriores oportunidades de expandirme sobre varias cuestiones que idealmente requieren un tratamiento más detenido, algunas de ellas mencionadas en sesiones de discusión o por los dictaminadores. 
conclusión es que las atribuciones de seguir una regla no son "factuales" o semánticamente declarativas. En este trabajo presentaré y examinaré un argumento análogo, cuya conclusión es que las oraciones en que se atribuye a una persona la posesión de un fundamento epistémico para creer algo no son semánticamente declarativas. (Este argumento, como se verá, es independiente del argumento kripkeano, y su conclusión es compatible con la falsedad de la conclusión del argumento kripkeano, así como con la "factualidad" de buena parte de las atribuciones intencionales en general.) Además del argumento mencionado, Kripke presenta una "solución escéptica" a la paradoja creada por su conclusión, "solución escéptica" que también atribuye a Wittgenstein. Como explicaré brevemente, puede enunciarse una "solución escéptica" análoga en el caso del argumento epistémico. Ambas "soluciones escépticas" tienen también consecuencias análogas acerca de la posibilidad de seguir una regla o tener un fundamento "privadamente"; estas consecuencias serán asimismo exploradas brevemente.

De la misma manera que Kripke en el caso de las reglas, no tengo la certeza de que el argumento antifactualista acerca de las atribuciones epistémicas o su "solución escéptica" sean correctos, y no deseo darlos por buenos meramente sobre la base de la exploración relativamente breve hecha en este trabajo. Mis tesis positivas son más cautas, si bien creo que poseen un interés suficiente por sí mismas. La primera es que el argumento antifactualista epistémico, así como la correspondiente "solución escéptica" y sus consecuencias (presentados todos ellos en la sección 2), tienen un interés intrínseco. La segunda tesis es que tanto las principales objeciones que se han hecho al argumento kripkeano como las concebibles objeciones análogas al argumento epistémico son inadecuadas (sección 3); además, la consideración de las objeciones en el caso epistémico clarifica las razones por las que las principales objeciones que se han hecho al argumento kripkeano son débiles. La tercera tesis es que el examen arroja luz sobre la adecuación exegética del argumento y la "solución" kripkeanos; específicamente sostendré, entre otras cosas (sección 4), que en Sobre la certeza Wittgenstein argumenta en contra de la posibilidad de tener un fundamento "privadamente" de la forma inspirada analógicamente por la lectura kripkeana; esto sugerirá de una manera indirecta que el texto kripkeano es seguramente más adecuado como exégesis de las Investigaciones de lo que se suele pensar.

En la sección 1 recapitularé brevemente el argumento de Kripke, su "solución escéptica" y las implicaciones de ésta acerca de la posibilidad de seguir una regla "privadamente". 


\section{El Wittgenstein de Kripke}

\subsection{El argumento antifactualista}

En la formulación que nos interesará primariamente aquí, la conclusión del argumento que Kripke atribuye a Wittgenstein es que las atribuciones de la forma de

(R) Sigo la regla $r$ (al hacer $a$ )

y de su versión en tercera persona, 'Fulano sigue la regla $r$ (al hacer $a$ )', no son semánticamente declarativas, no describen hechos (ni siquiera cuando son intuitivamente verdaderas). En la formulación que Kripke utiliza más a menudo, la conclusión antifactualista es acerca de las atribuciones de la forma 'Actúo de acuerdo con mi intención previa acerca de cómo usar el signo $s$ ' y otras atribuciones de intenciones, deseos y estados mentales intencionales en general. Pero las analogías que quiero explorar salen a la luz más fácilmente cuando uno se concentra en las atribuciones de seguir reglas. Por otro lado, vale la pena notar que, en contra de lo que se suele decir, Kripke nunca alude a la posibilidad de aplicar su argumento a atribuciones "intencionales" impersonales; por ejemplo, "La palabra "mesa' significa mesa". Como veremos, no hay razón para pensar que Kripke haya pretendido que su argumento se extienda a este tipo de atribuciones impersonales.

El argumento utiliza una premisa básica: si existe el hecho de que sigo la regla $r$ (al hacer $a$ ), ese hecho debe consistir al menos en parte en la existencia de una cosa que me es directamente accesible y que me proporciona una justificación (en sentido amplio) para hacer $a .{ }^{1}$ Aquí que algo sea "directamente accesible" quiere decir simplemente que su existencia no me es conocida de forma conjetural, de la manera en que me es conocida la existencia de muchos objetos postulados por la ciencia empírica, como los electrones, las neuronas, los genes o los traumas infantiles, sino en virtud de mi conocimiento ordinario y con un alto grado de certeza intuitiva. Por otro lado, cuando en la premisa se habla de "justificación en sentido amplio", se quiere establecer un contraste con tipos específicos de justificaciones más frecuentemente tratadas en filosofía, como las morales o las epistémicas. La justificación que para una acción proporciona una regla no tiene por qué ser moral ni epistémica: piénsese, por ejemplo, en la justificación que para mi enroque largo proporciona la regla correspondiente del ajedrez. Pero, como otros tipos de justificaciones, la proporcionada por una regla me muestra que en virtud de ella puedo (y en algunos casos

\footnotetext{
${ }^{1}$ La premisa o requisito fundamental de Kripke es que el hecho de que sigo la regla $r$ consiste en parte en la existencia de algo que me justifica cuando hago a (cfr. Kripke 1982, pp. $11 ; 40 ; 52$, n. 34; 87, etc.). Que ese algo ha de ser directamente accesible se sigue de que me proporciona una justificación (cfr. Kripke 1982, p. 40).
} 
incluso debo) realizar cierta acción. (En este sentido, la existencia de esa justificación tiene una implicación normativa, aunque la normatividad en cuestión no sea moral ni epistémica.)

La premisa básica recoge, sin duda, una intuición fundamental acerca de uno de los usos de las atribuciones de seguir una regla, la intuición de que (en el uso pertinente de la expresión) la persona que sigue una regla es guiada, de manera plenamente consciente, por esa regla en la realización de una acción. Seguramente hay usos aceptables de las atribuciones de seguir una regla con los que no se busca atribuir la posesión de esa guía u orientación consciente proporcionada por la regla. Podemos decir "Los planetas siguen las reglas de la mecánica celeste", o "Ese perro está tan bien adiestrado que sigue las reglas elementales de la urbanidad", o incluso "Kasparov sigue las reglas del ajedrez inconscientemente". Pero a menudo queremos decir algo más. A esos usos en los cuales queremos decir algo más se aplica el argumento kripkeano.

$\mathrm{El}$ argumento procede enumerando una serie de cosas que me son directamente accesibles y mostrando en cada caso que ninguna de ellas me proporciona una justificación para realizar ninguna acción en particular, pues no me muestran que pueda realizar ninguna acción en particular. Así, por ejemplo, una "expresión mental" de la regla no me proporciona una justificación para realizar acción alguna en particular, pues es susceptible de múltiples interpretaciones. Esto quiere decir que nada en la "expresión mental" misma me orienta a actuar de una manera más bien que de otra enteramente diferente. Para continuar con el ejemplo del ajedrez, aunque "tenga en mente" el algoritmo o regla habitual $r$ para realizar la acción $a$ del enroque largo, regla formulada en términos de expresiones como 'columna', 'rey', 'alfil', etc., $r$ considerada en sí misma no me muestra que pueda mover el rey a la columna del alfil de dama en lugar de la del caballo de dama. Sólo lo puede hacer si interpreto $r$; por ejemplo, por medio de reglas acerca de qué llamar 'caballo' y qué 'alfil'. Y naturalmente puedo interpretar estas expresiones de múltiples maneras, incluidas muchas según las cuales llamaré 'caballos' a los alfiles y 'alfiles' a los caballos. Si nada en $r$ excluye varias interpretaciones de sus expresiones, $r$ no me proporciona una justificación para realizar $a$.

Una posibilidad es que, aunque $r$ en sí no me proporcione una justificación para realizar $a$, una cadena $\left(r_{1}, r_{2}, \ldots, r_{n}\right)$ de reglas, donde $r=r_{1} \mathrm{y}$ $r_{i+1}$ parece servir para "interpretar" $r_{i}$, sí me proporcione una justificación para hacer $a$. Sin embargo, está claro que esta cadena de reglas tampoco me proporciona una justificación para hacer $a$, pues $r_{n}$ es susceptible de múltiples interpretaciones. Asimismo, no es menos claro que sólo puedo apelar a cadenas finitas de "reglas para interpretar reglas". Si mi acción $a$ es guiada por alguna regla, ha de ser guiada en último término por una regla "básica", o sea una regla que no interpreto por medio de otra regla. 
Así pues, si $r_{n}$ es una regla "básica", que no interpreto por medio de otra, y el hecho de que sigo la regla original $r$ existe, ha de haber alguna cosa adicional que me sirve para interpretar $r_{n}$ pero que no sea ella misma una regla. Kripke considera y descarta varios candidatos "directamente accesibles" a ser esa cosa adicional, cosas tales como sensaciones, impresiones, imágenes, etc., de nuevo porque son susceptibles de múltiples interpretaciones. Por ejemplo, es quizá un hecho acerca de mí o incluso acerca de muchos de mis congéneres humanos que una determinada "imagen mental" de un alfil se me presenta cada vez que considero la regla $r_{n}$, que podemos suponer es la regla que utilizo para aplicar la palabra 'alfil'. Sin embargo, esa supuesta imagen no me proporciona una justificación para llamar 'alfil' a los alfiles y no, digamos, a los caballos. De nuevo puedo interpretar esa imagen de múltiples maneras, incluidas muchas según las cuales la aparición de la imagen junto a la regla para 'alfil' autoriza a llamar 'alfiles' a los caballos.

Vale la pena recordar que Kripke también concede cierta atención a la sugerencia de que al menos ciertas atribuciones intencionales personales describen la existencia de ciertas disposiciones. Por ejemplo, podría sugerirse que "Sigo la regla del enroque largo al enrocarme" describe en parte la existencia de una disposición mía a enrocarme en determinadas circunstancias. Si bien Kripke objeta esta propuesta de otras maneras, su objeción fundamental es que la propuesta no satisface la premisa básica de su argumento. ${ }^{2}$ La existencia de una disposición semejante, aun si fuera posible, no tiene por qué consistir en parte en la existencia de una cosa que me es directamente accesible y que me proporciona una justificación para enrocarme. La disposición misma, en particular, ni es directamente accesible ni tiene ninguna capacidad de guiar mi aplicación de la regla del enroque largo (o cualquier otra regla).

Kripke considera que esta enumeración crítica agota las cosas conocidas directamente de las que podría pensarse a primera vista que son capaces de proporcionar una justificación como la exigida en la premisa básica del argumento. Al no haber encontrado un hecho con esta característica mencionada en la premisa básica, Kripke aplica modus tollens y concluye

\footnotetext{
${ }^{2}$ Como es bien sabido, Kripke también objeta la propuesta disposicionalista negando que un ser humano tenga disposiciones infinitas (y también que tenga disposiciones infalibles); por ejemplo, la disposición a enrocarse en las posiciones permitidas en el número potencialmente infinito de partidas que podría jugar. Como Kripke señala repetidamente, este tipo de consideraciones, basadas en la finitud de la mente humana y la infinitud de las aplicaciones potenciales de las reglas, son relativamente secundarias para sus propósitos si se las compara con las objeciones basadas en la imposibilidad de encontrar cosas con poder justificatorio (véase, v.gr., Kripke 1982, pp. 23; 52, n. 34, y 87). Pero muchos lectores de Kripke parecen haber pensado que las objeciones basadas en la idea de finitud son las objeciones kripkeanas fundamentales, en algunos casos con consecuencias negativas para la apreciación exacta del argumento.
} 
que el hecho no existe, y que las atribuciones de seguir reglas no son semánticamente declarativas.

\subsection{La "solución escéptica" y el argumento del lenguaje privado}

Kripke atribuye a Wittgenstein una "solución escéptica" del argumento anterior. Es "escéptica" en el sentido de que consiste en dar una explicación de las atribuciones de seguir reglas que acepta la conclusión "escéptica" del argumento, según la cual su significado no es declarativo y su función no es descriptiva. (Esta conclusión es "escéptica" porque pone en duda una creencia usual.) De esta solución, anuncia Kripke, se sigue la tesis wittgensteiniana de que uno no puede seguir una regla "privadamente".

La "solución escéptica" ofrece en primer lugar condiciones de afirmabilidad de las atribuciones de seguir una regla, condiciones que no presuponen o implican que esas atribuciones sean declarativas o descriptivas. Kripke da condiciones muy toscas, que sólo indican la naturaleza aproximada de las condiciones que se deberían enunciar como resultado de una investigación más detallada. Pero las condiciones toscas son suficientes para sus propósitos. Son las siguientes:

(1p) (R) es afirmable por mí cuando, al hacer $a$, reacciono simplemente de la manera en que me siento inclinado a reaccionar a $r$.

(3p) 'Fulano sigue la regla $r$ (al hacer $a$ )' es afirmable por Mengano cuando, al hacer $a$, Fulano reacciona simplemente a $r$ de la misma manera en que Mengano se siente inclinado a reaccionar, y en casos anteriores ha reaccionado a $r$ simplemente de la misma manera en que Mengano se siente inclinado a reaccionar.

Una razón por la que (1p) y (3p) son toscas es que no mencionan algunas circunstancias que en contextos determinados parecen necesarias para la afirmabilidad de las correspondientes atribuciones. Por ejemplo, en el caso de (3p), generalmente la afirmabilidad de 'Fulano sigue la regla $r$ (al hacer $a$ )' requerirá algunos signos adicionales de que Fulano no está actuando "mecánicamente". Pero, en cualquier caso, estos refinamientos no añadirían nada sustantivo para los propósitos inmediatos de Kripke.

En segundo lugar, la "solución escéptica" ofrece una explicación de la función de un juego de lenguaje de atribuciones con las condiciones de afirmabilidad mencionadas. La función de un juego de lenguaje de atribuciones con las condiciones de afirmabilidad de las atribuciones de seguir reglas es, según el Wittgenstein de Kripke, proporcionar un instrumento de coordinación social. Si profiero (R), doy a los demás una indicación de que mi acción $a$ es una que en último término hago en virtud de mis reacciones primitivas a $r$. Esto es útil para los demás, que extraen de ello 
elementos de juicio sobre si reaccionaré a $r$ de maneras previsibles en el futuro. Si aceptan mi proferencia (R) por medio de una atribución de tercera persona, ellos indicarán a su vez (a otros o a mí) que confían en que mis reacciones a $r$ coinciden con las que ellos también se inclinan a tener de manera primitiva. Si rechazan mi proferencia $(R)$ por medio de la negación de una atribución de tercera persona, indicarán que desconfían de que yo vaya a reaccionar a $r$ como ellos.

Según Kripke, la explicación de las condiciones de afirmabilidad y de la función de las atribuciones de seguir reglas la expone Wittgenstein de maneras más o menos explícitas antes de la sección 202 de las Investigaciones filosóficas. ${ }^{3}$ Obsérvese ahora que, según el Wittgenstein de Kripke, (R) tiene en esencia la misma condición de afirmabilidad que

$\left(\mathrm{R}^{*}\right)$ Al hacer $a$, reacciono simplemente de la manera en que me siento inclinado a reaccionar a $r$,

y también aproximadamente la misma que

$\left(\mathrm{R}^{* *}\right) \mathrm{Al}$ hacer $a$, reacciono de la manera en que creo que consiste seguir la regla $r$.

Según Kripke, lo que Wittgenstein hace en 202 es notar que la existencia intuitiva de una diferencia sustantiva entre $(R)$ y $\left(R^{* *}\right)$ sugiere en sí misma que mi uso de (R) no es "privado", es decir, que puede ser evaluado en principio por otros de tal manera que, también en principio, ellos pueden discrepar de mi proferencia (R) (como propone la "solución escéptica" en su descripción de la función de las atribuciones de seguir reglas). Wittgenstein parece claramente presuponer (como afirma la "solución escéptica") que $(R)$ y $\left(R^{* *}\right)$ no describen hechos diferentes (si lo hicieran, ahí habría una diferencia), y además que $(\mathrm{R})$ y $\left(\mathrm{R}^{* *}\right)$ tienen las mismas condiciones de afirmabilidad (si fueran diferentes, de nuevo esa sería una diferencia sustantiva). Puesto que $(\mathrm{R})$ y $\left(\mathrm{R}^{* *}\right)$ son sustancialmente distintas, esto parece implicar que su diferencia ha de radicar en que otros pueden evaluar y discrepar de mi proferencia (R) (indicando con esa discrepancia lo señalado en la "solución"). Por otro lado, esa discrepancia no se producirá con $\left(\mathrm{R}^{* *}\right){ }^{4}$

\footnotetext{
3 “Y por tanto también 'seguir una regla' es una práctica. Y creer que uno sigue una regla no es seguir una regla. Por tanto no es posible seguir una regla 'privadamente': de otro modo creer que uno está siguiendo una regla sería lo mismo que seguirla" (Wittgenstein 1958, $\S 202$; en adelante, Investigaciones filosóficas se abreviará con $I F$, seguido del número de la sección).

${ }^{4}$ Puede discreparse de $\left(\mathrm{R}^{* *}\right)$ en casos en que hay la sospecha de que el que profiere $\left(\mathrm{R}^{* *}\right)$ no domina el concepto de creencia (por ejemplo). Lo relevante es que, si se supone que el hablante domina todos los conceptos que aparecen en $\left(R^{* *}\right)$ y $(R)$, incluido el concepto general de "seguir una regla", podremos discrepar de su proferencia de (R) pero no discreparemos de su proferencia de $\left(\mathrm{R}^{* *}\right)$.
} 
Kripke también dice que, en las secciones 258 ss. de las Investigaciones, ${ }^{5}$ Wittgenstein simplemente hace una aplicación particular de la tesis general de que mi uso de (R) no es "privado", pero ahora en contra de un objetor que pretende que en el caso de los términos para sensaciones hay ciertas cosas llamadas 'definiciones ostensivas privadas' que sí me proporcionan una justificación para aplicar esos términos en casos particulares.

\section{Una concepción antifactualista de las atribuciones epistémicas}

\subsection{El argumento antifactualista epistémico}

La conclusión del argumento antifactualista epistémico que exploraremos aquí es que las atribuciones de la forma de

\section{(F) Tengo a $f$ como fundamento para creer que $p$}

y de su versión en tercera persona, 'Fulano tiene a $f$ como fundamento para creer que $p$ ', no son semánticamente declarativas, no describen hechos (ni siquiera cuando son intuitivamente verdaderas). Observemos que estas atribuciones mencionan al menos una noción correspondiente a un tipo de estado mental intencional consciente, la creencia. Por ello, el argumento kripkeano de la sección anterior quizá se aplique a ellas de alguna manera indirecta. Sin embargo, uno de los aspectos interesantes del argumento de la presente sección es que llega a su conclusión antifactualista sin apelar en ningún momento a la conclusión del argumento kripkeano. Además, la conclusión del argumento epistémico es por supuesto compatible con la "factualidad" de las atribuciones intencionales en general, y en particular con la "factualidad" de las atribuciones de creencia. Esta característica del argumento epistémico tiene importancia, dado que el argumento kripkeano es controvertido (aunque ha sido criticado sobre todo con base en objeciones que en realidad son débiles, algunas de las cuales mencionaremos en la sección 3).

${ }^{5}$ IF 258: "Imaginemos la situación siguiente. Quiero llevar un diario acerca de la recurrencia de una sensación. Con este fin, la asocio con el signo 'E' y escribo este signo en un calendario cada día que tengo la sensación.-En primer lugar observaré que no puede formularse una definición del signo. Pero aun así puedo darme a mí mismo una especie de definición ostensiva.-¿Cómo? ¿Puedo señalar la sensación? No en el sentido habitual. Pero pronuncio o escribo el signo, y al mismo tiempo concentro mi atención en la sensación-y así, por así decir, la señalo internamente.-¿Pero para qué es esta ceremonia? iPues a eso parece reducirse! Una definición sin duda sirve para fijar el significado de un signo.-Bien, eso se consigue precisamente al concentrar mi atención; pues de esta manera me imprimo a mí mismo la conexión entre el signo y la sensación.-Pero 'me la imprimo a mí mismo' sólo puede querer decir: este proceso comporta que recuerdo correctamente la conexión en el futuro. Pero en la situación presente no tengo criterio de corrección. Uno querría decir: lo que me parezca correcto es correcto. Y eso sólo quiere decir que aquí no podemos hablar de 'correcto'." 
El argumento epistémico utiliza, como su análogo, una premisa básica: si existe el hecho de que tengo a $f$ como fundamento para creer que $p$, ese hecho debe consistir al menos en parte en la existencia de una cosa que me es directamente accesible y que hace que para mí esté justificado (en sentido epistémico) creer que $p$. La justificación proporcionada por el fundamento pertinente es epistémica, en el sentido de que mi posesión del fundamento me muestra que puedo creer que $p$, en el sentido específico de que constituye para mí una indicación suficiente de la verdad de $p$.

Nuevamente esta premisa básica recoge una intuición central acerca de uno de los usos de las atribuciones de tener un fundamento, la intuición de que (en el uso pertinente de la expresión) la persona que tiene el fundamento para creer que $p$ recibe de éste un apoyo comprensible y del que es plenamente consciente para creer que $p$ es verdadera. Quizá hay usos aceptables de las atribuciones de tener un fundamento con los que no se busca atribuir la posesión consciente de ese apoyo proporcionado por el fundamento pertinente. Quizá podemos decir, de la computadora que juega al ajedrez conmigo, que tiene un fundamento para creer que su siguiente mejor jugada es el enroque; por ejemplo, el conjunto de cálculos que ha realizado en los segundos precedentes. O quizá podemos decir, de mi gata Drashá, que su fundamento para creer que hay comida disponible es su percepción del platillo en el que se la pongo normalmente. Pero a menudo queremos decir algo más. A esos usos en los cuales queremos decir algo más se aplica el argumento de esta sección.

Así pues, la noción de "tener un fundamento" sobre la que versan las consideraciones de este trabajo es una noción "internista", en el sentido de que los fundamentos en cuestión y la justificación que proporcionan son comprensibles y accesibles conscientemente al sujeto de la creencia potencial. Como es sabido, un buen número de epistemólogos, especialmente desde los años setenta del siglo $\mathrm{xx}$, han propuesto que algunas nociones epistémicas concebibles no son "internistas". No es éste el lugar de entrar en la polémica entre "internistas" y "externistas". Quizá algunos usos ordinarios de las palabras 'fundamento', 'apoyo', 'justificación', etc., no son "internistas"; y ciertamente (y en especial) varios usos técnicos de esas palabras que han adquirido prominencia tras el trabajo de los epistemólogos "externistas" no son "internistas". ${ }^{6}$ Pero, en mi opinión, como he dicho,

\footnotetext{
${ }^{6}$ Conceptos de este tipo aparecen incluso en la obra de epistemólogos "internistas". Por ejemplo, siguiendo a Tyler Burge (1993), podemos llamar 'derechos' [entitlements] a aquellos apoyos justificatorios para una creencia que no son comprendidos por o siquiera accesibles para el sujeto de la creencia. Burge, que no rechaza una concepción "internista" de la justificación epistémica, señala que la gente a menudo en algún sentido "tiene derecho" a creer ciertas proposiciones incluso si no posee un fundamento para ellas. Sin embargo, aun en el sentido de Burge, el que alguien tenga o al menos sea capaz de obtener un fundamento comprensible y accesible para una creencia determinada es una condición necesaria para que otra persona "tenga el derecho" (en el sentido filosófico de Burge) a formar esa creencia. El argumento
} 
una intuición central acerca de al menos algunos de los usos ordinarios de las atribuciones de tener un fundamento es que la noción en juego es claramente "internista". Y ciertamente aún hoy una mayoría de epistemólogos comparte al menos esta tesis débil. El argumento de esta sección se aplica a la noción de "tener un fundamento" que es relevante para esta mayoría de epistemólogos. Si el argumento es convincente, o incluso si no es claramente incorrecto, su importancia para cualquier concepción epistemológica "internista" será obvia. ${ }^{7}$

El argumento antifactualista epistémico procede enumerando una serie de cosas que me son directamente accesibles y mostrando en cada caso que ninguna de ellas me proporciona una justificación para adoptar creencia particular alguna. Podemos suponer (siguiendo el uso ordinario y al Wittgenstein de Sobre la certeza) que los fundamentos son siempre creencias, aun si los apoyos epistémicos puedan ser cosas de otros tipos. Cuando $f$ es una creencia que constituye un fundamento intuitivo para creer que $p$, $f$ no puede, sin embargo, proporcionarme por sí sola una justificación, pues puedo haberla adoptado por absoluto azar, de manera que por sí sola no me muestra que pueda creer nada en particular.

Por otro lado, una cadena $\left(f_{1}, f_{2}, \ldots, f_{n}\right)$ de creencias, donde $f=f_{1} \mathrm{y}$ $f_{i+1}$ parece hacer que para mí esté justificado tener la creencia $f_{i}$ tampoco puede constituir el apoyo que necesito, pues puedo tener la creencia $f_{n}$ por absoluto azar. Asimismo, no es menos claro que sólo puedo apelar a cadenas finitas de "fundamentos para justificar fundamentos". Si mi creencia $p$ se apoya en algún fundamento, ha de ser en último término en un fundamento "básico", o sea en un fundamento que no recibe apoyo de ningún otro fundamento.

Así pues, si $f_{n}$ es una creencia que no justifico por medio de otra, y el hecho de que tengo a $f$ como fundamento existe, ha de haber alguna cosa adicional que sirve para justificar $f_{n}$ pero que no sea ella misma una creencia. El resto del argumento consiste en enumerar una serie de candidatos concebibles y descartar en cada caso su capacidad justificatoria.

Cuando $f_{n}$ es a priori, cabe quizá pensar que mi apoyo para adoptarla pueda en algunos casos constituirlo mi acto de estipular o formar la intención de que cierta oración que expresa la proposición creída sea verdadera. Esta intención sería, según esta idea, lo que justificaría mi creencia en la proposición expresada por la oración. La objeción básica a esta idea es que el mero hecho de haber formado la intención de tratar como verdadera a

antifactualista se aplicará a la persona que (supuestamente) tiene el fundamento, incluso si no se aplica a la persona que (supuestamente) "tiene derecho" a la creencia.

${ }^{7}$ Los argumentos especiales de Kripke contra el disposicionalismo acerca de las atribuciones intencionales (basados en la observación de que las disposiciones humanas son finitas y falibles) también tienen análogos en el caso epistémico que pueden usarse para atacar varias concepciones epistemológicas "externistas". Dejo un examen de este asunto para otra ocasión. 
cierta oración no me muestra que esa oración pase a expresar una proposición. E, incluso si por algún otro medio recibo un apoyo para creer que expresa una proposición, mi intención en sí no me indica que es más probable que esa proposición sea verdadera que falsa. Además, naturalmente, si en un caso particular de estipulación poseo una proposición creída $q$ como aparente fundamento para creer que la oración en cuestión expresa una proposición, o incluso que expresa una proposición verdadera, estará claro una vez más que creer $q$ por sí solo no puede justificar la otra creencia, con lo cual volveré al estadio argumental del regreso de los fundamentos.

Otra propuesta para el caso de $f_{n}$ a priori es que el apoyo para adoptarla lo constituye, en algunos casos, mi comprensión de determinadas expresiones. La propuesta puede consistir meramente en tomar la noción de comprensión como fundamental o primitiva y explicar la posesión de un fundamento o de un apoyo justificatorio en términos de esa comprensión. Aquí la comprensión ha de ser o bien cierto tipo de saber proposicional, y por tanto una creencia, o al menos algún tipo de capacidad de adquirir creencias o usar oraciones de una manera justificada al menos en parte por la formación de intenciones lingüísticas. Esto también es inaceptable. Si la comprensión es un tipo de saber y por tanto de creencia justificada, cabe simplemente notar que el reto del argumento antifactualista es que exhiba la cosa que constituye el apoyo para una creencia de la que normalmente diríamos que está justificada para mí; el reto me embarca en un nuevo regreso o me deja donde estaba. Por tanto, podemos suponer que debemos entender la comprensión como cierto tipo de capacidad de adquirir creencias o usar oraciones de una manera justificada al menos en parte por la formación de intenciones lingüísticas. Pero, ¿cómo puede el hecho de que comprendo una oración mostrarme que puedo creer que la proposición que expresa es verdadera? Intuitivamente, el que yo comprenda una oración no me muestra típicamente que puedo creer la proposición que expresa. La propuesta ha de consistir en decir que en algunos casos peculiares la comprensión me proporciona esa justificación. Y la única manera en que esto podría ocurrir sería si la intención lingüística pertinente fuera justificatoria en algún sentido. Pero es difícil ver cómo una intención de usar oraciones con cierto significado pueda bastar para proporcionarme una razón para creer que esas oraciones son verdaderas, pues ni siquiera hace más probable por sí misma que adquieran un significado.

Si la propuesta es que la comprensión, cualquiera que sea su naturaleza, está en algunos casos constituida al menos en parte por la intención de mantener que ciertas "definiciones implícitas" son verdaderas, y que esta intención es responsable del poder justificatorio de la comprensión en estos casos, la propuesta es inaceptable por las mismas razones. La intención de sostener que cierta "definición implícita" es verdadera no me muestra que la "definición implícita" en cuestión exprese una verdad, y ni siquiera hace 
más probable que esa oración exprese una proposición. Y si poseo una proposición creída como aparente fundamento para creer que la oración en cuestión expresa una proposición verdadera, de nuevo ese aparente fundamento por sí solo no puede justificar dicha creencia, y volvemos al regreso de los fundamentos.

Pasemos ahora a considerar creencias a posteriori. Una posibilidad es que mi apoyo para creer algunas proposiciones de este tipo lo proporcionen mis experiencias o mis sensaciones. Puede parecer, por ejemplo, que $\mathrm{mi}$ apoyo para creer que algo me duele es precisamente mi dolor. Pero de nuevo está claro que una experiencia o una sensación no me muestran que puedo formar ninguna creencia en particular. A diferencia de una creencia, una experiencia o una sensación no me dicen cómo puedo reaccionar a ellas, pues ni siquiera poseen un contenido. Por tanto, no constituyen un apoyo para mis creencias. Una cuestión diferente es si yo tengo la creencia de que ciertas experiencias son una indicación confiable de la verdad de ciertas proposiciones. Esta creencia podría constituir un apoyo para formar ciertas creencias en la presencia de determinadas experiencias. Pero ello requeriría que esa creencia tuviera algún apoyo justificatorio a su vez, lo cual nos lleva de nuevo al estadio del regreso.

El mismo problema surge para la idea de que otros hechos no intencionales de los que soy directamente consciente constituyen apoyos epistémicos. Por ejemplo, podría pensarse que el hecho de que hay una silla delante de mí me muestra que puedo creer que hay una silla delante de mí. La objeción sigue siendo que ese hecho no me dice cómo puedo reaccionar a él, en el sentido de que no posee un contenido y por tanto no es susceptible de ejercer una influencia apropiada sobre una creencia.

Ocasionalmente se propone que el hecho (intencional) de que me parece que $p$ me muestra por sí solo que puedo creer que $p$. Por ejemplo, según esta idea, el hecho de que me parece que hay una silla delante de mí me muestra que puedo creer que hay una silla delante de mí. La objeción a esta idea es que el hecho de que me parece que $p$ no puede por sí sólo constituir indicación suficiente de que $p$, ya que es compatible con una situación en la que las apariencias engañan la mayoría de las veces. Sólo en presencia de una creencia fundamentada de que las apariencias son típicamente confiables puede el hecho de que me parece que $p$ mostrarme que puedo creer que $p$. Y naturalmente, una vez más, esa creencia requiere algún fundamento para poder fundamentar a su vez.

Es razonable pensar que esta enumeración crítica agota en esencia las cosas conocidas directamente de las que podría pensarse a primera vista que son capaces de proporcionar una justificación epistémica, en el sentido exigido en la premisa básica del argumento. Al no haber encontrado un hecho con esta característica mencionada en la premisa básica, se aplica modus tollens y el argumento concluye que el hecho no existe, y que 
las atribuciones de tener un fundamento no son semánticamente declarativas.

2.2. Una "solución escéptica" y sus implicaciones para la noción de privacidad

Es posible dar condiciones de afirmabilidad toscas para las atribuciones de tener un fundamento, inspiradas en las de (R) y su versión de tercera persona:

(F) es afirmable por mí cuando tengo la creencia $f$ y obtengo de $f$ una gran certeza para creer que $p$.

'Fulano tiene a $f$ como fundamento para creer que $p$ ' es afirmable por Mengano cuando Mengano cree que Fulano tiene la creencia $f$ y Mengano obtiene de $f$ una gran certeza para creer que $p$.

Ahora bien, a la mayoría de los epistemólogos, incluido Wittgenstein, les interesan sobre todo las atribuciones de saber, de la forma

(S) Sé que $p$,

no de "tener un fundamento". Pero hay una conexión inmediata entre ambos tipos de atribuciones, que además es análoga a la que hay entre (R) y

$\left(\mathrm{R}^{\prime}\right)$ Sigo una regla (al hacer $a$ ).

(S) y $\left(\mathrm{R}^{\prime}\right)$ comparten el rasgo de que parte de su contenido intuitivo viene dado por una proposición existencial: "Hay un fundamento que tengo para creer que $p$ " en el caso de (S) y "Hay una regla que sigo al hacer $a$ " en el caso de $\left(R^{\prime}\right)$. Y es inevitable pensar que si $(F)$ y $(R)$ no son semánticamente declarativas, entonces tampoco lo son $(S)$ ni $\left(R^{\prime}\right)$. Por ejemplo, si una atribución con la forma de $\left(\mathrm{R}^{\prime}\right)$ fuera semánticamente declarativa y verdadera, entonces algún caso particular suyo con la forma de (R) sería verdadero y semánticamente declarativo.

Es relativamente claro cómo dar condiciones de afirmabilidad toscas para $\left(R^{\prime}\right)$ y su versión de tercera persona inspiradas en las de (R) y su versión de tercera persona:

$\left(\mathrm{R}^{\prime}\right)$ es afirmable por mí cuando, al hacer $a$, reacciono a alguna regla simplemente de la manera en que me siento inclinado a reaccionar.

'Fulano sigue una regla (al hacer $a$ )' es afirmable por Mengano cuando, al hacer $a$, Fulano reacciona a alguna regla simplemente de la misma manera en que Mengano se siente inclinado a reaccionar, y en casos anteriores ha reaccionado a esa misma regla simplemente de la misma manera en que Mengano se siente inclinado a reaccionar, 
y cómo dar condiciones de afirmabilidad (muy toscas) para (S) y su versión en tercera persona inspiradas en las de $(F)$ y su versión de tercera persona:

(S) es afirmable por mí cuando creo que $p$ y apelo en último término a alguna creencia de la que obtengo una gran certeza para creer que $p$.

'Fulano sabe que $p$ ' es afirmable por Mengano cuando Mengano cree que $p$, cree que Fulano cree que $p$, y cree que Fulano apela en último término a alguna creencia de la que Mengano obtiene una gran certeza para creer que $p$.

También se puede proponer una explicación de la función de atribuciones con las condiciones de afirmabilidad de (F), (S) y sus versiones de tercera persona. De nuevo su función es proporcionar un instrumento de coordinación social. Por ejemplo, si profiero (S), doy a los demás una indicación de que mi creencia $p$ es una que en último término adopto apelando a creencias que simplemente me proporcionan una gran certeza para hacerlo. Esto es útil para los demás, que extraen de ello elementos de juicio sobre mis acciones futuras. Si aceptan mi proferencia (S) por medio de una atribución de tercera persona, ellos indicarán a su vez (a otros o a mí) que he adoptado $p$ apelando a creencias que también les proporcionan una gran certeza a ellos. Si rechazan mi proferencia (S) por medio de la negación de una atribución de tercera persona, indicarán que he adoptado $p$ apelando a creencias que no proporcionan una gran certeza para ellos, y por tanto que mi manera de adquirir creencias no es confiable.

Según esta "solución escéptica" del argumento antifactualista de la subsección 2.1, (S) tiene la misma condición de afirmabilidad que

$\left(\mathrm{S}^{*}\right)$ Creo que $p$ y apelo en último término a alguna cosa de la que obtengo una gran certeza para creer que $p$,

y también aproximadamente la misma que

$\left(\mathrm{S}^{* *}\right)$ Para mí es muy cierto que $p$.

Y la existencia intuitiva de una diferencia sustantiva entre (S) y $\left(\mathrm{S}^{*}\right)$ (o $\left(\mathrm{S}^{* *}\right)$ ) sugiere que mi uso de $(\mathrm{S})$ no es "privado", en el sentido de que puede ser evaluado en principio por otros de tal manera que, también en principio, ellos pueden discrepar de mi proferencia de (S) (como acaba de esbozarse en la descripción de la función de las atribuciones epistémicas), pero no de mis proferencias de $\left(\mathrm{S}^{*}\right)\left(\mathrm{o}\left(\mathrm{S}^{* *}\right)\right)$.

En la sección 4 veremos que hay buenas razones para pensar que Wittgenstein sostuvo este tipo de ideas en Sobre la certeza, lo cual sugiere también que tenía una concepción antifactualista de las atribuciones epistémicas. 


\section{Las acusaciones de incoherencia y de "reductivismo"}

Hay muchas objeciones concebibles a la concepción antifactualista de las atribuciones epistémicas expuesta en la sección 2. Algunas de ellas son lo que podríamos llamar objeciones "epistemológicas" al argumento de la subsección 2.1. Otras son lo que podríamos llamar objeciones "abstractas" a ese argumento. (Otras son objeciones, tanto "epistemológicas" como "abstractas", a la "solución escéptica" de la subsección 2.2, pero son comparativamente secundarias y no las trataré aquí por falta de espacio.)

La distinción entre objeciones "epistemológicas" y "abstractas" es simple. El argumento de la subsección 2.1 incorpora una serie de subargumentos o consideraciones específicas que aparecen en formas parecidas en la literatura del escepticismo epistemológico habitual. El argumento presente agrupa esas consideraciones y las pone al servicio de una conclusión diferente de la tesis del escéptico epistemológico típico. ${ }^{8} \mathrm{Al}$ constar parcialmente de consideraciones escépticas típicas, las objeciones concebibles al argumento antifactualista incluirán los intentos de responder a aquellas consideraciones que pueden hallarse en la literatura epistemológica antiescéptica. En este trabajo no examinaremos ninguna objeción de este tipo al argumento antifactualista. Una razón es simplemente que todas las respuestas conocidas a las consideraciones escépticas usadas en el argumento han sido y siguen siendo notoriamente infructuosas. (De hecho, la profusión de respuestas incompatibles y rebuscadas alimenta aún más la ya de por sí considerable fuerza persuasiva de las simples y elegantes consideraciones escépticas.) Pero la razón fundamental es que no parece apropiado examinar objeciones para las que ya existen contraobjeciones también en la literatura epistemológica. Por otro lado, es ciertamente apropiado examinar aquí objeciones potenciales al argumento que se basen en alguna característica abstracta, no puramente epistemológica, de sus premisas o razonamientos; en particular, es necesario explorar la posibilidad de construir objeciones convincentes al argumento que se basen en alguna

\footnotetext{
${ }^{8}$ Esta tesis, en su forma más habitual, es que el conocimiento es imposible: toda atribución de la forma de (S) o de la forma de 'Fulano sabe que $p$ ' es necesariamente falsa. Otra tesis escéptica radical, más fuerte, es que la posesión de un fundamento epistémico para una creencia es imposible: toda atribución de la forma de (F) o de la forma de 'Fulano tiene un fundamento para creer que $p$ ' es necesariamente falsa. El defensor del argumento de la subsección 2.1, por el contrario, no afirma que esas atribuciones sean falsas, sino en todo caso que no son susceptibles de ser verdaderas o falsas. Además, el proponente de la "solución escéptica", que acepta la conclusión del argumento antifactualista, ofrece una explicación de las condiciones de afirmabilidad y la función de esas atribuciones, explicación que busca iluminar nuestras ideas intuitivas acerca de su verdad o falsedad. Para el escéptico habitual, nuestro discurso epistémico consta de errores sistemáticos. Para el proponente de la "solución escéptica", nuestro discurso epistémico cumple una función no descriptiva muy definida, y no es sistemáticamente erróneo en ningún sentido.
} 
característica que comparta con el argumento análogo del Wittgenstein de Kripke.

Para quitarle probabilidad a esta posibilidad, examinaré críticamente las dos objeciones principales que se han hecho al argumento antifactualista kripkeano en la bibliografía especializada, la objeción de que su conclusión es incoherente y la acusación de que el argumento se basa en un "reductivismo" inapropiado. La primera me parece relativamente menor, es comparativamente improbable que pueda extenderse por analogía al caso del argumento epistémico, y se basa en una mala interpretación de Kripke. Aun así, creo que su irrelevancia para el argumento del Wittgenstein de Kripke queda especialmente manifiesta cuando se tiene en mente la analogía entre éste y el argumento epistémico. La acusación de "reductivismo" es más importante, porque no es tan obviamente inadecuada como la primera y porque hay una versión análoga para el caso epistémico. De todos modos, sostendré aquí que también esta objeción y su análoga son inadecuadas. En este caso pienso que la inadecuación de la objeción queda de nuevo más clara teniendo presente la analogía entre los dos argumentos antifactualistas.

\subsection{La acusación de incoherencia}

Una de las objeciones más extendidas al argumento de la subsección 1.1 es que su conclusión es contradictoria, y por tanto algún supuesto o patrón de razonamiento utilizado en el argumento ha de ser incorrecto, aun si la objeción no desvela cuál. Esta objeción es relevante para el argumento antifactualista epistémico. Dada la analogía entre éste y el argumento kripkeano, la objeción sugiere la posibilidad de que en el argumento epistémico sea incorrecto el supuesto o el patrón de razonamiento análogo al responsable de la incoherencia en el argumento kripkeano. Examinaré aquí dos versiones de la objeción, una debida a Paul Boghossian (1990) y la otra a Scott Soames (1998a) (en el caso de Soames, mi presentación será algo distinta de la suya). ${ }^{9}$

$\mathrm{El}$ argumento de Boghossian puede reconstruirse como sigue:

Premisa 1: Las premisas de Kripke o variantes apropiadas suyas pueden usarse para llegar a la conclusión de que las atribuciones intencionales en general, ya sean psicológicas y personales o no, no tienen un contenido declarativo real. Entre ellas están atribuciones de las formas de 'La oración $O$ significa que $p$ ', 'La oración $O$ describe un hecho', 'La oración $O$ tiene la condición de verdad $p$ ' y 'La oración $O$ es semánticamente declarativa'. Así, una de las conclusiones posibles es:

\footnotetext{
${ }^{9}$ Otra version de la objeción puede hallarse en Wright 1984, p. 769, pero el argumento de Wright no llega a una conclusión tan claramente inaceptable como las conclusiones de los argumentos empleados por Boghossian y Soames.
} 
$\left(\mathrm{K}^{*}\right)$ Ninguna oración de la forma 'La oración $O$ es semánticamente declarativa' es semánticamente declarativa.

De esto se sigue:

$\left(^{*}\right)$ La oración 'La oración $\left(\mathrm{K}^{*}\right)$ es semánticamente declarativa' no es semánticamente declarativa.

Premisa 2: Una presuposición de una tesis como $\left(\mathrm{K}^{*}\right)$ o $\left({ }^{*}\right)$ es que las oraciones de la forma de 'La oración $O$ es semánticamente declarativa' son semánticamente declarativas.

Boghossian dice que ello es así porque si $\left(\mathrm{K}^{*}\right)$ y $\left({ }^{*}\right)$ son verdaderas, esto sólo puede ser porque se presupone que el predicado 'es semánticamente declarativa' es "robusto" o "sustantivo" [non-deflationary] (aquí esto quiere decir, aproximadamente, que no se aplica automáticamente, por necesidad conceptual, a cualquier oración significativa que sea gramaticalmente declarativa). Y si ese predicado es "robusto", entonces expresa una "propiedad real". Y si expresa una "propiedad real", entonces las oraciones en las que se predica de una oración deben ser semánticamente declarativas.

De la premisa 2 se sigue:

${ }^{(* *}$ La oración 'La oración ( $\left.\mathrm{K}^{*}\right)$ es semánticamente declarativa' es semánticamente declarativa.

$\left({ }^{*}\right)$ y $\left(^{* *}\right)$ son contradictorias (cfr. Boghossian 1990, p. 175).

El argumento de Soames comparte su primera premisa con el de Boghossian, y también deriva una contradicción a partir de $\left(\mathrm{K}^{*}\right)$, pero su autor no lo propone como un argumento acerca de la noción "no robusta" o "insustantiva" de "ser semánticamente declarativa". Lo propone como un argumento acerca de la noción "insustantiva", que toma como la noción intuitiva, y concluye que no se debe pensar que el argumento de Kripke permite deducir $\left(\mathrm{K}^{*}\right)$ (entendida como una tesis acerca de la noción "insustantiva"). Seguramente Soames elude las especulaciones acerca de qué principios valen para la noción "sustantiva" que aparece en el argumento de Kripke (especulaciones como las que ofrece Boghossian para justificar su premisa 2). Pero en realidad el argumento de Soames usa sólo premisas que parecen razonables cuando se entienden como afirmaciones acerca de cualquier noción "sustantiva" de "ser semánticamente declarativa". Por ello es bueno considerar el argumento de Soames como una versión de la acusación de incoherencia, incluso si al hacerlo no representamos exactamente las intenciones originales del autor.

$\mathrm{El}$ argumento de Soames puede reconstruirse como sigue: 
Premisa 1: Las premisas de Kripke o variantes apropiadas pueden usarse para llegar a la conclusión de que las atribuciones intencionales en general, ya sean psicológicas y personales o no, no tienen contenido declarativo real. Así, una de las conclusiones posibles es:

$\left(\mathrm{K}^{*}\right)$ Ninguna oración de la forma 'La oración $O$ es semánticamente declarativa' es semánticamente declarativa.

Premisa 2: Puesto que $\left(\mathrm{K}^{*}\right)$ "se usa para hacer una afirmación teórica acerca de una cierta clase de oraciones" (Soames 1998a, p. 325), debe ser semánticamente declarativa.

Premisa 3: "Si $O$ y $O$ ' son negaciones la una de la otra" (p. 325), entonces una es semánticamente declarativa si la otra lo es.

De las premisas 2 y 3 se sigue que la negación de $\left(\mathrm{K}^{*}\right)$,

(No- $\left(\mathrm{K}^{*}\right)$ ) Alguna oración de la forma 'La oración $O$ es semánticamente declarativa' es semánticamente declarativa,

es semánticamente declarativa.

Premisa 4: Una generalización existencial es semánticamente declarativa sólo si alguno de sus casos particulares es semánticamente declarativo.

De la tesis de que (No- $\left.\left(\mathrm{K}^{*}\right)\right)$ es semánticamente declarativa y la premisa 4 se sigue que algún caso particular de (No- $\left.\left(\mathrm{K}^{*}\right)\right)$ es semánticamente declarativo, digamos

${ }^{* * *}$ ) La oración 'La oración $O_{0}$ es semánticamente declarativa' es semánticamente declarativa.

Pero de $\left(\mathrm{K}^{*}\right)$ se sigue que $\left({ }^{* *}\right)$ no es semánticamente declarativa; de aquí la contradicción (cfr. Soames 1998a, pp. 324-325).

Cabe hacer notar que los argumentos de Boghossian y Soames no pueden modificarse de ninguna manera obvia para generar una contradicción a partir de la conclusión del argumento epistémico. La conclusión de este argumento es:

Ninguna oración de la forma 'Tengo a $f$ como fundamento para creer que $p$ ' es semánticamente declarativa.

Pero es esencial para los argumentos de Boghossian y Soames que el predicado 'es semánticamente declarativa' aparezca en las oraciones de las que el proponente de la tesis antifactualista dice que no son semánticamente declarativas. Si se concede que el argumento epistémico no tiene ninguna implicación acerca de la declaratividad semántica de oraciones que contengan el predicado 'es semánticamente declarativa', habrá que conceder 
también que el argumento no es susceptible de recibir la acusación de incoherencia hecha al argumento kripkeano. Sin embargo, las cosas no son tan simples. Aunque no sea obvia, existe la posibilidad de que tanto el argumento kripkeano como el epistémico se basen en algún supuesto común responsable de la incoherencia y que tenga implicaciones acerca de la noción de declaratividad semántica. De hecho, como vamos a ver, Boghossian y Soames atribuyen a Kripke un supuesto con implicaciones directas de ese tipo. Podría pensarse que el argumento epistémico reposa veladamente en el mismo supuesto. Es necesario mostrar que no hay razón para pensar esto.

No haré aquí un examen crítico exhaustivo de los argumentos de Boghossian y Soames. Para los propósitos de este artículo bastará mostrar que la premisa 1 de estos argumentos no es verdadera. En otras palabras, $\left(\mathrm{K}^{*}\right)$ no es una conclusión obtenible por medio del argumento kripkeano o de alguna variante suya. Una vez mostrado esto, no tendremos razón para pensar que el argumento o su análogo epistémico tengan un supuesto incoherente.

Quizá vale la pena notar que, en algunos casos, la idea de que el argumento kripkeano se aplica a $\left(\mathrm{K}^{*}\right)$ y otras atribuciones intencionales no psicológicas o impersonales puede deberse a que la formulación principalmente usada por Kripke es acerca de la noción de intención lingüística, la noción de querer decir, en el sentido literal y no figurado de esta expresión en castellano (según el cual sólo una persona o un ser semejante puede querer decir algo por medio de una expresión). Esto puede haber creado en algunos casos la impresión errónea de que el argumento puede desarrollarse también para la noción figurada, no psicológica, de "querer decir", usada, por ejemplo, cuando afirmamos que la palabra 'albéitar' quiere decir veterinario. (En inglés ocurre algo parecido, pues el verbo usado por Kripke, to mean, es ambiguo entre dos sentidos literales, uno psicológico y otro no psicológico.) Y si el argumento puede desarrollarse para la noción no psicológica de "querer decir", entonces parecería que debería poder desarrollarse igualmente para otras nociones intencionales no psicológicas, incluida la noción de "ser semánticamente declarativa" que aparece en los argumentos de Boghossian y Soames.

Pero el argumento kripkeano no puede desarrollarse sin más para nociones no psicológicas como "ser semánticamente declarativa". Recuérdese que la premisa básica del argumento dice que si existe un hecho de un cierto tipo, entonces ese hecho consiste en parte en la existencia de algo directamente accesible y justificatorio. Esta premisa posee una considerable fuerza intuitiva cuando los hechos en cuestión son hechos intencionales psicológicos de ciertos tipos, como el hecho de que sigo la regla de la adición, o el hecho de que tengo el deseo consciente de comerme un caramelo, o el hecho de que tengo la creencia consciente de que hay un caramelo en 
el cajón; intuitivamente la regla de la adición guía mis sumas, y el deseo de comerme un caramelo junto con la creencia de que hay uno en el cajón guían mi acción de abrir el cajón. Pero, ¿hay intuiciones semejantes acerca del hecho de que la oración 'Hay un caramelo en el cajón' es semánticamente declarativa (o acerca del hecho de que significa que hay un caramelo en el cajón, o acerca del hecho de que es verdadera si y sólo si hay un caramelo en el cajón, etcétera)?

Algunos filósofos han sostenido con razones altamente teóricas que una oración no puede significar algo a menos que alguien, en algún momento, haya tenido algún tipo de intención lingüística acerca de ella. Sin embargo, ésta no es en absoluto una tesis intuitiva acerca de la noción de significado lingüístico. ¿Acaso no tenemos la intuición de que un grupo de humanos podría poseer un lenguaje con significado aun sin tener la noción de lo que es una palabra, y por tanto sin poder siquiera formar intenciones lingüísticas? De hecho la tesis mencionada es negada por una mayoría de filósofos; ${ }^{10}$ por ejemplo, es negada por los filósofos que, siguiendo a Wittgenstein, sostienen que el "uso" de las expresiones determina su significado lingüístico. Está claro, pues, que el que una oración signifique algo no requiere por necesidad conceptual que alguien, en algún momento, haya tenido algún tipo de intención lingüística acerca de ella. Sin embargo, es muy razonable pensar que hay una conexión analítica entre la proposición de que sigo la regla de la adición y la proposición de que existe algo que guía mis sumas. El argumento de Kripke sólo utiliza esta última conexión, y en ningún caso apela a la tesis de que el significado lingüístico requiere intenciones lingüísticas.

Lo que parece haber llevado a filósofos como Boghossian y Soames a sostener su premisa 1 no es la tesis recién rechazada, sino una interpretación errónea del argumento mismo de Kripke. Según esta interpretación, el argumento se apoyaría de algún modo en la tesis general de que ningún hecho tiene implicaciones normativas, y por tanto ninguna oración que describa un hecho tiene consecuencias normativas. Concedida esta tesis, el kripkeano imaginario razonaría como sigue. Las afirmaciones de la forma de 'La oración $O$ es semánticamente declarativa' tienen consecuencias normativas; por ejemplo, la consecuencia de que $O$ debería ser usada por los hablantes del lenguaje al que pertenece, al menos en casos típicos, cuando tienen la intención de comunicar el contenido declarativo de $O$. Pero, dado que ningún hecho tiene implicaciones normativas, las oraciones de la forma de 'La oración $O$ es semánticamente declarativa' no expresan hechos, no son semánticamente declarativas (cfr. Boghossian 1990, p. 172, n. 30; Boghossian 1989, p. 509; Soames 1998b, pp. 212 y 230-231).

\footnotetext{
${ }^{10}$ Boghossian mismo (1990, pp. 170-171) observa que un argumento antifactualista que reposara en un supuesto de esta naturaleza no sería convincente.
} 
Pero, independientemente de si el razonamiento del kripkeano imaginario es correcto o no, está claro que el argumento del Kripke real no usa en ningún momento la tesis general de que ningún hecho tiene implicaciones normativas. ${ }^{11}$ Como vimos en la subsección 1.1, Kripke apela a la tesis, defendida por el argumento, pero mucho más débil, de que sólo en virtud de ser consciente de las cosas que son "directamente accesibles" a mí no adquiero consciencia de ciertas implicaciones normativas intuitivas. Según Kripke, ese tipo de cosas "directamente accesibles" no me muestran que pueda o deba hacer nada en virtud de ellas. Esta tesis carece por completo de la generalidad de la tesis de que ningún hecho, sea "directamente accesible" o no, posee implicaciones normativas. (En particular, obsérvese que no es obligatorio sostener que el hecho de que una oración $O$ sea o no semánticamente declarativa, o sus supuestas implicaciones normativas, hayan de ser "directamente accesibles" a nadie; al fin y al cabo, si estos hechos fueran siempre directamente accesibles, la polémica suscitada por el argumento kripkeano no existiría.) La tesis de que algún hecho no psicológico tiene implicaciones normativas de algún tipo es compatible con el argumento kripkeano en la forma en que lo reconstruimos antes. ${ }^{12}$

Esta tesis de compatibilidad queda reforzada precisamente por la posibilidad de construir un argumento análogo al kripkeano y que también es aparentemente compatible con la tesis de que algún hecho no psicológico tiene implicaciones normativas. El argumento antifactualista epistémico procede mostrando que ninguna de una serie de cosas accesibles e inteligibles para mí en cuanto agente epistémico tienen para mí implicaciones normativas de carácter específicamente epistémico. Esta tesis es claramente compatible con la tesis de que algún hecho no accesible o inteligible para mí tiene implicaciones normativas. Si aceptamos la estrecha analogía entre los dos argumentos, lo mismo ocurre con el argumento antifactualista acerca de la noción de seguir reglas. Es difícil evitar concluir que la acusación de incoherencia se basa en una confusión básica acerca de la naturaleza del argumento kripkeano.

\subsection{La acusación de "reductivismo"}

Seguramente la objeción más popular al argumento de la subsección 1.1 se basa en la idea de que depende tácitamente de un inapropiado "re-

${ }^{11}$ José Zalabardo (1997) ha mostrado esto más allá de toda duda razonable. Específicamente, ha mostrado que los argumentos de Kripke no son acerca de una noción general de normatividad, sino acerca de una noción de justificación. (Discrepo, sin embargo, de Zalabardo en cuanto que éste entiende la noción de justificación en el argumento de Kripke en un sentido epistémico. Desde mi punto de vista, la noción de justificación en el argumento no es específicamente epistémica.)

${ }^{12}$ Y probablemente también lo es su negación. La cuestión de si hay o puede haber hechos con implicaciones normativas, así como la de sus posibles conexiones con los argumentos de Boghossian y Soames, se salen de los límites de este trabajo. 
ductivismo" de lo intencional a lo no intencional. Sin embargo, no parece haberse observado que la acusación de "reductivismo" ha sido construida de maneras contradictorias por los distintos autores que la han hecho. La naturaleza de esta contradicción revela una inestabilidad que en último término resta atractivo a esta acusación. Hay dos clases de críticos que la hacen. Los críticos del primer tipo aceptan la premisa básica del argumento kripkeano y los críticos del segundo tipo la niegan. El problema de los críticos del primer tipo es que las implicaciones de la premisa básica los fuerzan a hacer una interpretación restrictiva e inadecuada del resto del argumento kripkeano. Esto es concedido implícitamente por los críticos del segundo tipo. El problema de éstos, sin embargo, es que las razones que aducen permiten a lo sumo negar que la premisa básica sea satisfecha por una clase restrictiva de atribuciones intencionales, pero no por otras atribuciones de este tipo (incluidas las atribuciones de seguir una regla en sus usos centrales). Así pues, no existe en la literatura sobre el argumento kripkeano una objeción apropiada que se base en la acusación de "reductivismo". Esencialmente por razones análogas, concluiremos que no está claro cómo podría construirse una acusación de "reductivismo" contra el argumento antifactualista epistémico presentado en este trabajo.

Una acusación temprana de "reductivismo" se debe a Brian Loar (1985). Según Loar, el argumento kripkeano no es correcto, y sólo se convierte en correcto si uno añade alguna premisa que diga que lo intencional es "reducible" a lo no intencional:

¿no podría algún brentaniano acérrimo sostener que la intencionalidad irreducible es un hecho, que es un hecho que tenemos acceso directo a las propiedades intencionales irreducibles de nuestros pensamientos [...] y que la no arbitrariedad de nuestras aplicaciones de nuestros conceptos está conectada de alguna manera con esa accesibilidad? Parece que el argumento en defensa de la paradoja escéptica debe tener alguna premisa suprimida que diga que los "hechos" quedan agotados con los hechos de cierto tipo que excluye la intencionalidad irreducible — si lo prefiere el lector, los hechos naturalistas-. Pero ¿cómo especificar esta premisa? El fisicismo parece no wittgensteiniano. Kripke no trata la cuestión de esta premisa; pero, sin ella, ¿cómo podría haber un argumento que mostrara que el que queramos decir esto o aquello no es una cuestión de hecho? (Loar 1985, p. 276).

Loar señala que no es lógicamente necesario que los estados y procesos directamente accesibles queden agotados con los susceptibles de múltiples interpretaciones, y por tanto no es lógicamente necesario que ninguno de ellos pueda guiar mis aplicaciones de una regla. Según Loar, la posibilidad de múltiples interpretaciones es sólo plausible para estados o procesos "naturalistas" (o "descritos de forma naturalista"), pero no puede ser un rasgo de estados y procesos que son "irreduciblemente intencionales", esto es, 
estados y procesos de los que suponemos que, por su propia naturaleza, no son susceptibles de múltiples interpretaciones. Kripke omite considerar esta posibilidad lógica y su argumento falla. Nótese que Loar no rechaza la premisa básica, pues deja claro que lo que el antirreductivista debe sostener es que "es un hecho que tenemos acceso directo a las propiedades intencionales irreducibles de nuestros pensamientos y que la no arbitrariedad de nuestras aplicaciones de nuestros conceptos está conectada de alguna manera con esa accesibilidad". Antes del pasaje citado, Loar ha enunciado la premisa básica del argumento kripkeano sin cuestionarla: "nuestra concepción ordinaria del querer decir y el seguir una regla presupone [...] que el que queramos decir esto o aquello es una cuestión de hecho, y que lo que queremos decir nos guía" (Loar 1985, p. 275).

Quizá la presentación de Kripke pueda sugerir que sostiene que es lógicamente necesario que todos los estados y procesos directamente accesibles son susceptibles de múltiples interpretaciones. Pero en realidad no sostiene esto. (A lo sumo lo que sostiene es que, supuesta la finitud de la mente humana, es lógicamente necesario que ningún estado o proceso directamente accesible puede codificar una interpretación infinita para una expresión.) Obsérvese que, si lo sostuviera, sería difícil explicar por qué su argumento procede a través de una búsqueda y una correspondiente enumeración crítica de procesos y estados directamente accesibles. Sin duda, razona Kripke, si uno concede que una cosa me muestra con un alto grado de certeza que puedo realizar cierta acción, entonces esa cosa debe serme directamente accesible, y debo haberla tenido ante mí muy a menudo. El argumento de Kripke descansa en la tesis de que no se encuentra la cosa en cuestión. Contra esta tesis (si es correcta), la objeción de Loar es irrelevante, pues la tesis ciertamente no presupone una premisa "reductivista": si la cosa en cuestión ha estado ante mí a menudo guiándome, entonces, incluso si no puedo dar una descripción no demostrativa de ella excepto por medio de vocabulario intencional, debo al menos ser capaz de señalarla, de referirme a ella por medio de un demostrativo, como "esta" o "aquella" cosa; pero la tesis de Kripke es que no ha sido capaz de señalar ninguna cosa con las propiedades apropiadas, y en particular con el poder de guiarme $u$ ofrecerme una justificación.

Otro crítico del primer tipo es Boghossian. Según él, Kripke necesita:

o bien un argumento independiente que muestre que sólo las propiedades naturalistas son reales. $\mathrm{O}$, si no, un ataque frontal a la propiedad irreducible en cuestión, que muestre que es, en la expresión de Mackie, intrínsecamente "rara". La mayor debilidad del argumento escéptico de Kripke es que no cumple con ninguno de estos requisitos. Ni siquiera intenta defender un principio reduccionista acerca de lo intencional; y su breve intento de construir un argumento de "rareza" carece de entusiasmo y no es convincente. (Boghossian 1989, pp. 542-543) 
Como Loar, Boghossian dice que hace falta algún tipo de supuesto "reductivista" para que el argumento de Kripke funcione. A diferencia de Loar, sostiene que Kripke ha ofrecido algo (un "breve intento de construir un argumento de 'rareza' ") que, si fuera correcto, proporcionaría algún apoyo al argumento. Pero Boghossian niega que lo ofrecido por Kripke sea convincente. Boghossian se refiere a este texto de Kripke:

Quizá [el referirse a la adición con el signo 'más'] es simplemente un estado primitivo, que no se debe asimilar a sensaciones o dolores de cabeza o estados "cualitativos", y tampoco a disposiciones, sino un estado sui generis. Esta idea puede ser irrefutable en cierto sentido, y si se entiende de una manera apropiada Wittgenstein puede incluso aceptarla. Pero parece desesperada: hace a la naturaleza de este estado primitivo postulado [. . . completamente misteriosa. No se supone que es un estado introspectivo, y aun así se supone que somos conscientes de él con un alto grado de certeza cuando tiene lugar. Pues, ¿de qué otra manera puede cada uno de nosotros estar seguro de que se refiere a la adición con 'más'? Más importante aún es la dificultad lógica implícita en el argumento escéptico de Wittgenstein. [.. .] ¿Podemos concebir un estado finito que no se pudiera interpretar al estilo de la función tás? ¿Cómo podría ser eso? La propuesta que estoy comentando barre estas preguntas debajo de la alfombra, puesto que la naturaleza del supuesto 'estado' es misteriosa. $^{13}$

Aquí Kripke dice que el crítico que apele a cosas "irreducibles" debe responder satisfactoriamente a estas dos dificultades (en cursivas en el texto citado), y que es considerablemente difícil ver cómo se podría hacer esto. La primera dificultad corresponde al argumento de la "búsqueda fallida". (La segunda dificultad corresponde al otro tipo de argumento kripkeano mencionado, basado en el supuesto de que la mente humana es finita.)

La primera dificultad de Kripke es claramente malinterpretada por Boghossian: ${ }^{14}$

La primera acusación es que no tendríamos idea de cómo explicar nuestra capacidad de conocer nuestros propios pensamientos si adoptáramos una concepción no reduccionista de su contenido. Es cierto que todo el que haya examinado el problema del autoconocimiento quedará impresionado por su dificultad. Pero creo que se nos debería perdonar si, antes de permitir que

${ }^{13}$ Kripke 1982, pp. 51-53; las cursivas son mías. Recuérdese que la función tás de Kripke es una función aritmética que da los mismos valores que la adición para pares de argumentos menores que 57 y el valor 5 para todos los demás argumentos; Kripke supone que en el momento en que empiezo a buscar el hecho que constituye mi referirme a la adición con 'más' no he computado sumas con argumentos mayores que 56; puede suponer esto sin pérdida de generalidad, pues debe haber un número con esa propiedad.

${ }^{14}$ Boghossian también malinterpreta en buena medida la segunda dificultad, pero no comentaré esa mala interpretación aquí. 
esto nos lleve a un irrealismo acerca de la noción de contenido, irrealismo de dudosa coherencia, exigiéramos una prueba de que no es posible construir una epistemología satisfactoria. Kripke, sin embargo, no nos da tal prueba. Meramente nota que el carácter no fenoménico de los estados con contenido impide una explicación introspectiva de su epistemología. (Boghossian 1989, pp. 541-542)

Según Boghossian, la primera objeción de Kripke al "antirreductivista" es que su propuesta nos dejaría sin explicación de "nuestra capacidad de conocer nuestros propios pensamientos"; en la medida en que la falta de una explicación es "rara", esto sería una objeción de "rareza", pero extremadamente débil (como nota Boghossian), ya que Kripke no hace ni por asomo un examen crítico de explicaciones epistémicas potenciales. Sin embargo, la primera dificultad de Kripke no es que el autoconocimiento se convierta en difícil de explicar si uno abandona el "reductivismo", sino que, suponiendo la tesis intuitiva de que sabemos acerca de nosotros mismos lo que parece que sabemos (e independientemente de cuál sea la mejor explicación de ese conocimiento), no encontramos las cosas que supuestamente nos guían al seguir una regla. Intuitivamente, toda cosa de ese tipo es directamente accesible, de manera que "se supone que somos conscientes de ella con un alto grado de certeza cuando tiene lugar", como dice Kripke. El problema para el "antirreductivista" no es que no explique adecuadamente algo que intuitivamente está "ahí", sino que postula que hay algo que debe ser explicado pero que no hemos encontrado. Pues, ¿dónde está esa cosa directamente accesible y que me guía? Una vez más: debo poder señalarla si existe, pero no he sido capaz de hacerlo. Si esta lectura es correcta, la dificultad de Kripke no es realmente una objeción de "rareza".

Probablemente la mala interpretación de Boghossian emana de una lectura errónea de la siguiente oración de Kripke ("Pues, ¿de qué otra manera puede cada uno de nosotros estar seguro de que se refiere a la adición con 'más'?"). Boghossian parece haber leído esto como una pregunta retórica dirigida al antirreductivista, acerca de cómo explicar mi (auto)conocimiento de que me refiero a la adición con 'más', bajo el supuesto de que el hecho correspondiente no es un estado mental cualitativo o fenoménico. Pero está claro que Kripke no pregunta esto. Lo que Kripke hace es ofrecer, en la forma de una pregunta, una razón intuitiva para la accesibilidad directa del hecho de que me refiero a la adición con 'más': puesto que es una idea intuitiva que tengo una considerable certeza de que me refiero a la adición con 'más', ese hecho debe ser uno del que soy consciente "con un alto grado de certeza cuando tiene lugar". Pero si concedemos todas estas intuiciones acerca de la certeza y la accesibilidad directa, deberíamos poder encontrar ese hecho postulado por el "antirreductivista", 
si es que existe. La primera dificultad de Kripke, una vez más, es que no la ha encontrado. ${ }^{15}$

Un hipotético crítico del argumento epistémico de la subsección 2.1 podría aceptar su premisa básica pero negarle validez razonando que no excluye la posibilidad de que haya apoyos epistémicos "irreducibles", o no caracterizables excepto como "apoyos epistémicos" o "cosas que justifican creencias". Hay que subrayar que la propuesta de este crítico sería inadecuada por las mismas razones que en el caso de las reglas. El argumento epistémico llega a su conclusión después de una búsqueda fallida de cosas que pudieran constituir apoyos epistémicos en el sentido requerido por la premisa básica. Esa búsqueda no se restringe a cosas "reducibles" a lo no epistémico, o "naturalistas", etc., sino meramente a la clase de cosas accesibles e inteligibles para mí en cuanto agente epistémico. Creo que en el caso epistémico la propuesta "antirreductivista" suena prima facie incluso menos atractiva que en el caso de las reglas, posiblemente porque parece más claramente dogmática o incluso oscurantista para alguien que acepte la premisa básica. Una explicación de esta apariencia de dogmatismo u oscurantismo es que la propuesta no es conciliable con el supuesto de que los apoyos epistémicos han de ser plenamente accesibles e inteligibles para el sujeto epistémico. Al menos, no es conciliable para quien ha hecho una búsqueda cuidadosa pero fallida de esos apoyos epistémicos. Si esta explicación es correcta, el caso de las reglas no debería parecernos sustancialmente diferente. Aceptar la premisa básica del argumento kripkeano, pero postular la existencia de cosas "irreducibles" que nos guían en nuestra aplicación de las reglas, no es parte de una sana actitud "antirreductivista", sino más bien parte de una actitud prácticamente incoherente (y oscurantista en la medida en que la incoherencia es oscurantista). Quizá el que el caso de las reglas haya parecido sustancialmente diferente del caso epistémico se haya debido a una comprensión inadecuada de la esencia del argumento de Kripke. (Recuérdese la interpretación errónea mencionada en la subsección 3.1.) Por ello, hacer manifiesta la analogía entre los dos casos aclara otra vez la inadecuación de una objeción al argumento kripkeano.

Este tipo de consideraciones han sido implícitamente aceptadas por la segunda clase de críticos "antirreductivistas" del argumento kripkeano. Uno de ellos es Crispin Wright (1984). A diferencia de Loar y Boghossian, Wright no cree que el argumento kripkeano sea incorrecto en virtud de carecer de una premisa "antirreductivista". Wright concede que si aceptamos la premisa básica, entonces el argumento kripkeano funciona. Pero niega que una característica intuitiva de los hechos de intención sea que consten

\footnotetext{
15 En general, Boghossian (1989) no trata satisfactoriamente el argumento kripkeano, pues no hace justicia a la importancia fundamental que en él tiene la noción de justificación. Sin embargo, Boghossian es consciente de la premisa básica kripkeana y no la niega.
} 
en parte de algo que me muestre que puedo o debo realizar cierta acción. (Recordemos que la formulación del argumento antifactualista empleada más a menudo por Kripke es acerca de la noción de intención, específicamente acerca de la noción de intención lingüística, la noción de querer decir.) Wright da sus razones para esto en el siguiente pasaje:

Un poco de reflexión muestra que [...] la no-inferencialidad [...] [es] simplemente característica de nuestra noción intuitiva común de intención. Normalmente, se nos concede una autoridad especial en lo que hace al carácter de nuestras propias intenciones; si se nos pregunta acerca de ellas, se considera que deberíamos saber la respuesta, y que, exceptuando mentiras y lapsus, se debe dar un peso especial a nuestras respuestas. [.. .] Pensar en el autoconocimiento de la intención, en un caso en que al sujeto se le concede autoridad, como algo que se basa invariablemente en la inferencia a partir de pensamientos asociados es caricaturizar la noción ordinaria. Para empezar, todos llevamos a cabo regularmente actos intencionales sin pensar necesariamente en lo que estamos haciendo. [.. .] Pero la consideración decisiva es ésta. Incluso cuando una intención es acompañada por ciertos pensamientos acerca de su contenido o de las circunstancias del curso (previsto) de la acción, el conocimiento que uno tiene del carácter de la intención no debe verse como algo alcanzado a través de la reflexión sobre el contenido de esos pensamientos. [...] Es al revés: uno reconoce la especificación que los pensamientos hacen del contenido de una intención que uno tiene porque uno sabe en qué consiste la intención. (Wright 1984, pp. 775-776)

La manera en que esto afecta al argumento kripkeano se desarrolla en un pasaje posterior:

Así pues, para rechazar el argumento escéptico, habría bastado, en el momento en el que el escéptico te retó a encontrar algún hecho mental recordado que suprimiera las interpretaciones al estilo de [tás], recordar tu anterior intención con respecto al uso de ['más']. Sin duda, cualquier especificación que pudieras dar del contenido de esa intención sería susceptible de interpretaciones no deseadas. Pero si se te concede el uso de la noción intuitiva de intención, puedes replicar que en ningún caso conoces el contenido de una intención a través de una especificación suya; más bien reconoces la adecuación de la especificación porque conoces el contenido de la intención. (Wright 1984, p. 777)

A diferencia de Loar y Boghossian, Wright percibe correctamente que, si se concede la premisa básica de Kripke, tomada como una premisa acerca de "la noción intuitiva común de intención", entonces su argumento funciona ("sin duda, cualquier especificación que pudieras dar del contenido de esa intención sería susceptible de interpretaciones no deseadas") —en realidad, Wright parece atribuir al argumento una fuerza lógica superior a la que el mismo Kripke le atribuye-. Por tanto, Wright niega la premisa, 
y en particular niega que una intención sea algo por inferencia a partir de lo cual llegamos a ser conscientes de la posibilidad u obligatoriedad (o de la adecuación con respecto al contenido) de las acciones supuestamente guiadas por esa intención. Por el contrario, dice Wright, incluso si hay algunos sucesos mentales que acompañan mis acciones, mi conocimiento de (o mi estar dispuesto a decir) que tengo una cierta intención en virtud de la cual las realizo es independiente de esos sucesos. Si se concede la tesis de la "no inferencialidad", el argumento kripkeano no es bueno, pues se basa en una premisa falsa. Como dice Wright en el segundo de los pasajes citados, si poseo la noción "irreducible" de intención, puedo responder al Wittgenstein de Kripke diciendo que no hay una cosa que me guía cuando actúo de acuerdo con una intención: simplemente actúo de acuerdo con una intención, y sé que lo hago, pero eso es todo.

Una objeción "antirreductivista" parecida a la de Wright ha sido propuesta por Barry Stroud (1996), quien reconoce de manera completamente explícita que la premisa básica de Kripke es suficiente, en esencia, para establecer la conclusión del argumento, y por tanto que el objetor debe rechazarla:

La posibilidad de interpretaciones al estilo de "tás" de sonidos o marcas u otras cosas consigue refutar toda teoría del querer decir o la comprensión que requiera que haya una cosa en la "mente" de un hablante u oyente que le diga qué hacer al usar o responder a una expresión. Ninguna cosa semejante podría determinar la respuesta del hablante o el oyente, o su corrección. [... .] Pero si el requisito de "instrucción" o "guía" se ha suprimido en una teoría del querer decir o la comprensión, como debe ocurrir según Wittgenstein, ¿qué apoyo queda para la idea "escéptica"? La posibilidad de que 'más' pudiera querer decir tás sólo muestra que los hechos de querer decir o de comprensión o de corrección de la respuesta no se siguen y, por tanto, no son reducibles a sucesos descritos no intencionalmente. (Stroud 1996, p. 311)

De manera similar a Wright, Stroud señala que rechazar la premisa básica de Kripke abre el camino a una respuesta simple a su argumento: nada me guía, simplemente tengo una intención, incluso si no puedo especificar nada que me muestre que puedo actuar como actúo; cuando apunto a algo en mi mente, ese algo es siempre susceptible de múltiples interpretaciones, pero el hecho de que tengo una intención existe, sólo puede ser descrito en esos términos, y no tiene ningún poder justificatorio.

Nótese que las posturas de Wright y Stroud se apoyan en una tesis correcta, establecida precisamente en el curso del argumento del Wittgenstein de Kripke: no hay, en efecto, cosas que justifiquen nuestras acciones supuestamente guiadas por reglas. Esta tesis es común al argumento kripkeano y a este tipo de críticos. Sin embargo, la diferencia entre Kripke y estos críticos debe radicar en una tesis acerca del significado de las atribucio- 
nes intencionales; según Kripke, si el significado de ciertos usos de algunas de esas atribuciones es declarativo, entonces la verdad de esas atribuciones en esos usos requiere la existencia de cosas con poder justificatorio; según los críticos, todas esas atribuciones tienen significado declarativo y pueden ser verdaderas independientemente de la existencia de cosas de ese tipo.

Como ya señalamos en nuestra presentación de la subsección 1.1, el argumento kripkeano no se aplica a todos los usos de las atribuciones intencionales, y ni siquiera se aplica a todos los usos de las atribuciones intencionales psicológicas, sino sólo a algunos de ellos. Proponer lo contrario sería absurdo en cualquier caso. Hay incluso usos o acepciones de las atribuciones de seguir una regla a los que no se aplica el argumento kripkeano, incluidos usos que podríamos calificar como psicológicos; por ejemplo, "Kasparov sigue las reglas del ajedrez inconscientemente". El caso de las atribuciones de intención, en el que se concentra Wright, no es diferente, y de hecho pueden usarse incluso de más maneras que las atribuciones de seguir una regla. Así, podemos decir, por ejemplo, "Mi gata Drashá tenía desde hace rato la intención de comer, pero se lo impedía su hermana Fenixa". Igualmente podemos decir "Fulano agarró el tenedor intencionalmente", lo cual es intuitivamente verdadero aunque al afirmarlo no queramos decir ni siquiera en parte que a Fulano se le pasara por la cabeza el concepto de tenedor. Observaciones similares valen para muchos otros tipos de atribuciones intencionales psicológicas, incluidas las atribuciones de intenciones lingüísticas en las que se concentra específicamente Stroud. Si le digo a Fulano "Me voy al banco a descansar" y noto que Fulano se queda un poco confundido, puedo aclararle la situación diciendo "Me refería al banco del parque", aunque con ello no le quiero decir que se me había pasado por la cabeza ningún pensamiento acerca de la referencia que pretendía darle a la palabra 'banco'.

¿Es posible extraer de estos ejemplos la conclusión de que el argumento kripkeano no se aplica a ningún uso central de al menos ciertas atribuciones intencionales? En primer lugar, la existencia de los ejemplos no excluye por sí misma la existencia de usos que satisfagan la premisa básica. Aquí es útil comparar los ejemplos con ejemplos análogos en el ámbito epistémico. Yo puedo decir "Mi gata Drashá sabe que hay comida para ella", lo cual parece ser verdadero aunque seguramente con mi afirmación no atribuyo a Drashá la posesión de fundamentos para su creencia. Si alguien observa que viajé sin una manta en la maleta, puede afirmar "Este hombre sabía que habría una manta en la cama del hotel", aunque no quiera decir con ello que se me había pasado por la cabeza pensar acerca de eso, y por tanto mucho menos que yo poseía un fundamento consciente para creer que habría una manta en la cama del hotel. Parece claro que usos como éstos no afectan al argumento antifactualista epistémico, pues no son usos centrales de las atribuciones de saber. De la misma manera, una "solución" al escepticis- 
mo epistemológico tradicional que se basara meramente en ejemplos como éstos sería justamente condenada como irrelevante. El escéptico epistemológico tradicional concedería que en esos usos no afirmamos la posesión de un fundamento consciente por parte del sujeto de la atribución, y respondería simplemente que los usos de la noción de saber que le interesan son usos en los que sí afirmamos eso. Los ejemplos acerca de la noción de intención no excluyen que la situación en el caso intencional sea similar.

Y la situación es de hecho similar. Está claro que hay usos centrales de ciertas atribuciones intencionales de los que es simplemente antiintuitivo negar que satisfagan la premisa básica del argumento kripkeano. Cuando nos concentramos en estos usos, la postura de Wright y Stroud es difícil de sostener, por ser incompatible con la concepción razonable del contenido literal de las oraciones declarativas. Los usos de las atribuciones intencionales a los que se aplica el argumento kripkeano son usos de los que no es razonable sostener que su contenido declarativo literal podría ser verdadero sin que ello implicara la existencia de cosas con poder justificatorio, simplemente porque en ese caso afirmarían literalmente esa existencia. Considérense las siguientes atribuciones:

Estoy siguiendo de una manera plenamente consciente la regla de la adición al hacer estas sumas, y de la regla derivo mi justificación para mi proceder.

Me estoy guiando por la regla de la adición al hacer estas sumas.

Mi justificación para hacer estas sumas me la proporciona la regla de la adición.

Obviamente, todas ellas son intuitivamente verdaderas (en circunstancias apropiadas), pero es antiintuitivo sostener que pueden ser realmente verdaderas independientemente de la existencia de cosas con poder justificatorio. Ciertamente la "solución escéptica" acepta que esas cosas no existen, pero propone que la impresión de que las atribuciones son verdaderas es equivocada y se debe sólo a que son usadas correctamente, de acuerdo con sus condiciones de afirmabilidad. Wright y Stroud tienen que sostener que son verdaderas, pero su concepción los fuerza a sostener que describen hechos diferentes de los hechos indicados por su contenido literal, pues estos últimos hechos nunca se dan realmente. Esta postura sólo se puede sostener en conjunción con una concepción implausible del contenido literal de las oraciones declarativas.

Una vez más la debilidad de una crítica al argumento kripkeano queda iluminada por la analogía con el argumento epistémico. ¿Podría objetarse al argumento antifactualista o al escéptico epistemológico habitual de una manera análoga a la de Wright y Stroud, diciendo que las atribuciones típicas de saber y de tener fundamentos son semánticamente declarativas 
y verdaderas, pero no hay en realidad fundamentos o apoyos epistémicos para ninguna creencia? ${ }^{16}$ Seguramente esta objeción sería considerada absurda o irrelevante para la cuestión epistemológica. A lo sumo, se tomaría como una indicación de que el objetor tiene en mente alguna noción de la que no se está hablando realmente (quizá una noción técnica "externista"). Tanto el proponente del argumento antifactualista como el escéptico habitual se limitarían a observar que la objeción depende de supuestos semánticos sin motivación independiente y que parecen simplemente antiintuitivos para los usos relevantes y centrales de las atribuciones epistémicas. (Nótese que el objetor no propondría meramente que los hechos epistémicos admiten una redescripción en un vocabulario distinto; lo que propondría es que las atribuciones epistémicas son verdaderas (cuando lo son) aunque nunca se dan los hechos indicados por su contenido literal intuitivo. Así como la propuesta "redescripcionista" no es obviamente incorrecta, la incorrección de la propuesta del objetor se sigue simplemente si uno acepta que, si las atribuciones epistémicas pertinentes son semánticamente declarativas, entonces describen los hechos que parecen describir.)

\section{La concepción antifactualista y la epistemología wittgensteiniana}

Las interpretaciones antikripkeanas de las secciones centrales de las Investigaciones filosóficas disfrutan de una reputación exegética considerablemente mejor que la interpretación de Kripke. Y la idea de que la interpretación de Kripke no es fiel a las intenciones de Wittgenstein se usa a menudo para sostener que el argumento kripkeano y su "solución escéptica" no se ven respaldados por un "argumento de autoridad" (la autoridad de Wittgenstein), y por tanto quedan en alguna medida desacreditados incluso desde un punto de vista puramente filosófico.

De la misma manera que el argumento kripkeano y su "solución escéptica" están inspirados en Wittgenstein, el argumento antifactualista epistémico y su "solución escéptica" están inspirados en pasajes epistemológicos wittgensteinianos. En esta sección daré razones textuales para pensar que el argumento y la "solución" epistémicos son wittgensteinianos, razones que son particularmente potentes en el caso de la "solución escéptica" y sus consecuencias acerca de la noción de "privacidad". Esto arrojará nueva luz sobre el valor exegético de las ideas de Kripke acerca del caso de las

\footnotetext{
${ }^{16}$ Según un dictaminador anónimo de Diánoia, Wright ha intentado desarrollar una concepción epistemológica de este tipo en trabajos recientes. Confío en poder examinar críticamente estas ideas de Wright en el futuro. Por el momento debo conformarme con señalar que la a menudo aceptada objeción "antirreductivista" de autores como Wright al argumento kripkeano (y por consiguiente la concebible objeción análoga al argumento antifactualista epistémico) lleva necesariamente implícita una tesis implausible que está lejos de formar parte de la "noción intuitiva" de intención de la que hablaba Wright.
} 
reglas. En particular, sugerirá que el argumento kripkeano y su "solución" son más wittgensteinianos de lo que se suele pensar. Defenderé primero de manera comparativamente breve la tesis de que el argumento epistémico es wittgensteiniano, y luego me concentraré especialmente en la tesis de que su "solución escéptica" también lo es.

\subsection{El argumento antifactualista de Wittgenstein}

En Sobre la certeza, Wittgenstein se interesa especialmente por las atribuciones de saber en las que el uso de 'saber' está estrechamente vinculado a la noción de creencia justificada o fundamentada. Éste es también el sentido que Wittgenstein aísla especialmente en pasajes como el siguiente: "Uno dice 'Yo sé' cuando está dispuesto a dar fundamentos convincentes. 'Yo sé' se relaciona con la posibilidad de demostrar la verdad." 17 O éste: "Yo sé' a menudo significa: Tengo los fundamentos apropiados para mi afirmación" (SC 18). El núcleo del argumento antifactualista, recordémoslo, es que "las justificaciones se acaban en algún lugar", para usar una frase wittgensteiniana (cfr. IF 326: "Esperamos esto, y nos sorprende aquello. Pero la cadena de razones tiene un final", y SC 166: "La dificultad es darnos cuenta de que nuestro creer carece de fundamentos"). En el caso epistémico esto significa que, aunque el poder justificatorio de cosas tales como las proposiciones creídas que supuestamente justifican mi creencia de que $p$ depende intuitivamente de que estén justificadas por otros fundamentos, en realidad debo alcanzar un punto en el que el regreso se detiene; en ese punto me encontraré con una proposición u otra cosa sin fundamento. Dada la observación adicional de que estas cosas no tienen poder justificatorio por sí mismas, se ve que mi creencia de que $p$ es en último término "ciega".

Wittgenstein resume el argumento antifactualista en el siguiente pasaje de SC 204, que es una especie de análogo epistémico de (el segundo párrafo de) la famosa sección 201 de las Investigaciones: "Dar fundamentos, sin embargo, justificar nuestras razones, llega a un final; - pero el final no consiste en que ciertas proposiciones nos resulten inmediatamente verdaderas, es decir, no es una especie de visión por nuestra parte; es nuestro actuar lo que se halla en el fondo del juego de lenguaje." La búsqueda de la cosa que nos muestra que podemos creer cierta proposición nos embarca en un regreso de fundamentos, un regreso que debe acabar. Pero su fin no es una cosa que "vemos". Su fin es simplemente nuestro actuar "ciegamente" de una manera determinada. Nuestro actuar, esto es, aceptando ciertas creencias, llamando a estas creencias 'fundamentos', y haciendo todo ello en acuerdo con las condiciones de afirmabilidad para las atribuciones de "tener un fundamento" (y sus negaciones).

\footnotetext{
17 Wittgenstein 1969, § 243; en adelante, Sobre la certeza se citará SC seguido del número de la sección.
} 
La posibilidad de que una experiencia sea una cosa con poder justificatorio es claramente rechazada por Wittgenstein en $S C$ :

130. [. . . ¿ ¿cómo nos enseña entonces la experiencia? Nosotros podemos derivar [nuestros juicios] de la experiencia, pero la experiencia no nos instruye sobre cómo derivar algo de la experiencia. Si es el fundamento de que juzguemos así, y no simplemente la causa, aun entonces no tenemos un fundamento para ver esto a su vez como un fundamento.

131. No, la experiencia no es el fundamento para nuestro juego de juz$\operatorname{gar}[\ldots]$

(Nótese la analogía entre las frases 'una regla para interpretar una regla' y 'un fundamento para ver esto como un fundamento'.) En éste y otros textos, Wittgenstein usa 'experiencia' para referirse no a un suceso de experiencia aislado, sino a una serie de sucesos de experiencia del mismo tipo. Su objeción se aplica tanto al caso general como al caso específico: ni una serie recurrente de experiencias ni una experiencia en la serie nos muestran en ningún sentido que podamos adoptar una creencia. (Este caso es diferente del de una inducción basada no en una serie de experiencias, sino en una serie de creencias de experiencia. Este último caso queda cubierto en el estadio del regreso de los fundamentos: una serie de creencias de experiencia sólo puede justificar una generalización inductiva por medio de alguna ley inductiva que debe estar justificada en sí misma.) Véase también SC 145: "Uno querría decir 'Todas mis experiencias muestran que es así'. Pero ¿cómo lo hacen? Pues la proposición a la que apuntan pertenece en sí misma a una interpretación particular de ellas. 'El hecho de que considero a esta proposición como cierta caracteriza también mi interpretación de la experiencia."”

La idea de que la experiencia no nos muestra cómo formar creencias aparece también en la discusión de la noción de justificación epistémica en IF 477 ss. (una discusión que acaba de subrayar el regreso sin fundamento último de los fundamentos epistémicos): "486. ¿Se sigue de las impresiones de los sentidos que recibo que hay una silla allí?-¿Cómo puede seguirse una proposición de impresiones de los sentidos? [...] —Pero, ¿no infiero que hay una mesa allí de impresiones, de datos de los sentidos?-iNo hago ninguna inferencia!" Sin duda, ninguna creencia puede recibir su justificación de impresiones de los sentidos. Incluso una proposición que describa impresiones de los sentidos (y no mesas o sillas) no puede ser justificada meramente por esas impresiones - aunque Wittgenstein no menciona esta consecuencia de su idea más general-.

Como Kripke en el caso de las reglas, Wittgenstein concede alguna atención a los intentos "disposicionalistas" o en general "naturalistas" de ubicar el hecho de que tengo un fundamento para cierta creencia. Los rechaza 
vigorosamente, observando que no explican que hablemos de cosas por consideración de las cuales fundamentamos nuestros juicios:

¿Pero no es simplemente que seguimos el principio de que lo que ha ocurrido siempre ocurrirá otra vez (o algo así)? ¿Qué quiere decir seguir este principio? ¿Lo introducimos realmente en nuestro razonamiento? ¿O es meramente la ley natural que aparentemente sigue nuestro inferir? Puede ser esto último. No es una cosa que aparezca en nuestras consideraciones. (SC 135)

Quizá alguien diga "Debe haber algún principio básico en virtud del cual llegamos a nuestras creencias", pero ¿qué puede explicar este principio? ¿Es más que una ley del concepto de "tomar como verdadero"? (SC 172)

Las interpretaciones que toman a Wittgenstein como un disposicionalista o un "regularista" de algún tipo son frecuentes en la literatura sobre el caso de las reglas (véase más adelante). Pero el hecho de que Wittgenstein claramente no es un disposicionalista o un "regularista" en el caso epistémico sugiere, por analogía, que no es un disposicionalista o un "regularista" en el caso de las atribuciones de seguir una regla.

\subsection{El lenguaje privado y el saber privado}

A pesar de su mejor reputación, no cabe duda de que las exégesis antikripkeanas de Wittgenstein no ofrecen una interpretación satisfactoria de la temprana aparición de la noción de privacidad en IF 202. Así, por ejemplo, McGinn (1984) sostiene que en 202 'privado' no significa "no cognoscible por otros" o ningún otro concepto que tenga que ver con "los otros", y debe de tener un significado inhabitual. En su vehemente texto antikripkeano, Baker y Hacker (1984) dicen, en esencia, que la noción de privacidad aparece por error en 202, ya que el texto de esa sección aparecía después del de la sección 258 en manuscritos wittgensteinianos anteriores. Aquí señalaré algunas tensiones exegéticas de las interpretaciones antikripkeanas de las consideraciones sobre la noción de privacidad, sirviéndome de McGinn como adversario. (Pero las tensiones son comunes a varios antikripkeanos.) Luego señalaré un apoyo para una interpretación kripkeana: la existencia de un argumento kripkeano acerca de la noción de privacidad en Sobre la certeza.

Según McGinn, al llegar a 202 Wittgenstein sólo ha excluido que el hecho de que sigo una regla deba constar de una cosa "directamente accesible" de los tipos considerados en el argumento antifactualista del Wittgenstein de Kripke. Pero Wittgenstein no sólo no ha defendido un argumento antifactualista, sino que ha señalado claramente que (R) describe (cuando es verdadera) el hecho de que ejemplifico una regularidad conductual $R C$ ("cuando una persona sigue una señal (digamos), su conducta es su seguir 
la regla" (McGinn 1984, p. 36)). Sin embargo, no ha excluido la posibilidad de que $R C$ sea una regularidad privada, no cognoscible por otros. Esto se excluye en la sección 258, cuya conclusión es, según McGinn, que $R C$ debe ser una regularidad cuya existencia es comprobable por otros. En 202 Wittgenstein usa 'privado' de una manera inhabitual, como sinónimo de 'infalible', y simplemente argumenta que (R) no describe algo de cuyo darse tengo conocimiento infalible, como ocurriría si describiera el hecho de que tengo una cierta sensación, o impresión, etc. (cfr. McGinn 1984, p. 44). Según McGinn, al llegar a 202 Wittgenstein no tiene a su disposición ninguna idea que le permita extraer una conclusión acerca de "los otros".

En mi opinión, estas tesis son mucho más dudosas que las de la exégesis kripkeana. La identificación de las "prácticas" de Wittgenstein con meras regularidades conductuales es altamente dudosa (como mínimo) en vista de secciones como IF 200, 222 y 232. Además, secciones como 217 parecen excluir una interpretación según la cual una concepción factualista de las atribuciones de seguir reglas no implica que el hecho de seguir una regla no consiste al menos en parte en la existencia de una cosa "directamente accesible" que me guía. Además, la sección 201 introduce mención implícita de "los otros" cuando habla de que mi seguir una regla es exhibido ( $i a$ quién sino a otros?) en lo que nosotros llamamos 'seguir la regla' (sin duda no es un plural mayestático). Y la postulación de un uso inhabitual de "privado' en 202 que no tiene nada que ver con "los otros" es manifiestamente ad hoc.

En cualquier caso, la interpretación de McGinn encuentra problemas también en IF 258. Se supone que aquí Wittgenstein concluye tácitamente que sólo las regularidades conductuales no privadas (en el uso de signos) son casos de seguir una regla (cfr. McGinn 1984, p. 48). Pero, aparentemente, en 258 Wittgenstein dice simplemente que una "definición ostensiva privada" no sirve más para guiarme o darme una justificación que cosas esencialmente similares como "expresiones mentales", "impresiones", etc. Y la conclusión explícita es que si eso es todo lo que tengo, entonces no hay una distinción entre mi seguir una regla y mi creer que sigo una. La conclusión de 258 no menciona regularidades en absoluto, y de hecho la razón ofrecida para decir que una "definición ostensiva privada" es inapropiada es claramente compatible con que yo ejemplifique una regularidad conductual (privada o no). La única tesis del pasaje es que las "definiciones ostensivas privadas" no pueden ser la base para la distinguibilidad requerida; el pasaje no apoya una exégesis que apele a la noción de regularidad.

Aún más problemático para la interpretación de McGinn es el hecho de que debe apelar también a una premisa tácita en su reconstrucción de 258. Específicamente, debe apelar a una premisa verificacionista, que 
afirme que sea posible en principio que alguien pueda determinar si se da la regularidad ejemplificada por quien sigue la regla. El que McGinn reconozca que esa premisa es necesaria confirma la compatibilidad del contenido explícito de 258 con la posibilidad de que mi seguir la regla consista en que ejemplifico una regularidad. Desde luego, si la premisa tácita de McGinn excluye que mi seguir la regla consista en que ejemplifico una regularidad no verificable, entonces, dada su lectura anterior de Wittgenstein, se concluye que mi seguir la regla consiste en que ejemplifico una regularidad verificable y, por tanto, pública: y ésa es la conclusión de McGinn. Pero parece claro que una lectura con tantos entendidos tácitos no debería convencer a nadie.

Dados todos estos serios problemas, sería deseable encontrar apoyos para una lectura kripkeana alternativa. Hemos visto que, para Wittgenstein, $\left(R^{\prime}\right)$ y $(S)$ comparten la característica de que parte de su contenido intuitivo lo da una tesis existencial: "Hay un fundamento que tengo para creer que $p$ " en el caso de (S) y "Hay una regla que sigo al hacer $a$ " en el caso de $\left(\mathrm{R}^{\prime}\right)$. Además, en ambos casos hablamos intuitivamente de la relación entre fundamento y creencia y de la relación entre regla y aplicación como relaciones de "justificación", entendiendo este término de un modo epistémico restringido en el primer caso y en un sentido amplio en el segundo caso. Finalmente, y éste es el punto crucial: en ambos casos mi consideración de cosas potencialmente justificatorias me embarca en un regreso de justificaciones, pero "las justificaciones se acaban en algún lugar"; en ese lugar tampoco encuentro las cosas justificatorias que busco, lo cual implica que en realidad tanto mi seguir reglas como mi saber algo se dan "a ciegas". Wittgenstein mismo señala que el caso de las reglas es análogo al caso epistémico en este aspecto (véase SC 510-511, 111, 307).

Estos argumentos por sí mismos sugieren dos preguntas análogas. Cuando llevo a cabo cierta conducta $a$ que en realidad es ciega, aunque sería descrita intuitivamente como una aplicación de una regla, (P1) ¿por qué sigo una regla al llevar a cabo $a$, y no actúo simplemente de una manera que debería ser descrita como "ciega", meramente creyendo que sigo una regla? Cuando acepto cierta proposición $p$ que en realidad acepto a ciegas aunque sería descrita intuitivamente como sabida o creída por mí con un fundamento, (P2) ¿por qué sé que $p$, y no es simplemente el caso que acepto $p$ con una seguridad que debería describirse como ciega, meramente creyendo $p$ con suficiente certeza? Estas preguntas tienen como correlatos estrechamente relacionados preguntas acerca de atribuciones o afirmaciones: ( $\left.\mathrm{P}^{\prime}\right)$ En el primer caso, ¿̇cómo difiere sustantivamente mi afirmación (R) de mi afirmación $\left(\mathrm{R}^{*}\right)$ ? ( $\left.\mathrm{P} 2^{\prime}\right)$ En el segundo caso, ¿cómo difiere sustantivamente mi afirmación (S) de mi afirmación $\left(\mathrm{S}^{*}\right)\left(\mathrm{o}\left(\mathrm{S}^{* *}\right)\right)$ ? Una conexión entre (P1) y (P1'), por un lado, y entre (P2) y (P2'), por 
otro, es clara: para alguien que entiende que los argumentos acerca del regreso de las justificaciones establecen una conclusión antifactualista y la identidad de las condiciones de afirmabilidad de $(R)$ y $\left(R^{*}\right)$, por un lado, y de $(\mathrm{S})$ y $\left(\mathrm{S}^{*}\right)$, por otro, $\left(\mathrm{P} 1^{\prime}\right)$ es una versión rigurosa de $(\mathrm{P} 1)$, y $\left(\mathrm{P} 2^{\prime}\right)$ una versión rigurosa de (P2). (Por supuesto, un factualista también puede hacer todas estas preguntas.)

Según McGinn, la respuesta de Wittgenstein a (P1') es que (R) describe (cuando es verdadera) el hecho de que ejemplifico cierta regularidad conductual de la cual $a$ es un caso particular, mientras que $\left(\mathrm{R}^{*}\right)$ no lo hace. $\mathrm{Si}$ esta interpretación es correcta, debería esperarse que la respuesta de Wittgenstein a (P2') fuera que (S) describe (cuando es verdadera) el hecho de que ejemplifico una regularidad conductual de la que mi aceptar que $p$ es un caso particular. Presumiblemente, esta regularidad debería consistir en mi aceptación habitual de proposiciones similares a $p$ en algún aspecto pertinente: proposiciones que son verdaderas, o probablemente verdaderas, o - más plausiblemente- consecuencias del mismo tipo de fundamentos intuitivos, etc. $\left(\mathrm{S}^{*}\right)\left(\mathrm{y}\left(\mathrm{S}^{* *}\right)\right)$, sin embargo, describiría un hecho psicológico sin interés.

Por otro lado, la respuesta del Wittgenstein de Kripke a (P1') es que (R) y $\left(R^{*}\right)$ no difieren en que describan hechos diferentes; y no difieren tampoco en condiciones de afirmabilidad, pues en realidad no tengo un criterio que me permita distinguir el caso en que sigo una regla del caso en que no lo hago. Difieren en que otros podrían discrepar en principio de mi afirmación $(R)$ (pero no de mi afirmación $\left(R^{*}\right)$ ); si están de acuerdo con (R), esto junto con el hecho de que podrían haber discrepado implica que, incluso cuando son ambas afirmables, $(R)$ y $\left(R^{*}\right)$ difieren sustantivamente. Si esta interpretación es correcta, debería esperarse que la respuesta de Wittgenstein a (P2') fuera que (S) y $\left(\mathrm{S}^{*}\right)$ (o $\left(\mathrm{S}^{* *}\right)$ ) difieren en que otros pueden en principio discrepar de mi afirmación (S) (pero no de mi afirmación $\left(\mathrm{S}^{*}\right)$ (o $\left.\left(\mathrm{S}^{* *}\right)\right)$ ); si están de acuerdo con (S), esto junto con el hecho de que podrían haber discrepado implica que, incluso cuando son ambas afirmables, (S) y ( $\left.\mathrm{S}^{*}\right)$ (o $\left.\left(\mathrm{S}^{* *}\right)\right)$ difieren sustantivamente.

La respuesta de Wittgenstein a (P2') en Sobre la certeza parece ser la que uno esperaría de la analogía kripkeana:

245. ¿A quién le dice alguien que sabe algo? A sí mismo o a otro. Si se lo dice a sí mismo, ¿cómo se distingue de la afirmación de que está seguro de que las cosas son así? No hay seguridad subjetiva de que sé algo. La certeza es subjetiva, pero no el saber. Así, si digo "Sé que tengo dos manos", y se supone que eso no expresa sólo mi certeza subjetiva, debo poder convencerme a mí mismo de que estoy en lo correcto. Pero no puedo hacerlo, pues que tengo dos manos no es menos cierto antes de haberlas mirado que después. [... .] 
250. Que tengo dos manos es, en condiciones normales, tan cierto como cualquier cosa que pudiera proporcionar como apoyo para ello. Por tanto no puedo tomar el ver mi mano como un apoyo para ello.

251. ¿Acaso no significa esto: procederé de acuerdo con esta creencia incondicionalmente, y no dejaré que nada me confunda? Pero no se trata sólo de que yo creo de esta manera que tengo dos manos, sino que toda persona razonable lo cree. [...]

253. En el fundamento de la creencia fundamentada se halla una creencia que no está fundamentada.

254. Cualquier persona 'razonable' se comporta así.

La respuesta de Wittgenstein es significativa por varios motivos. En primer lugar, Wittgenstein da a entender que (S) y $\left(\mathrm{S}^{*}\right)$ (o $\left(\mathrm{S}^{* *}\right)$ ) no difieren en que la primera describa una regularidad conductual mía y la segunda no. En el caso epistémico está claro $-\mathrm{y}$ nadie parece haber pensado lo contrario- que a Wittgenstein no le tienta ninguna concepción regularista o similar (como vimos antes al citar SC 135 y 172). Por consiguiente, no hay duda de que no usa ninguna premisa acerca de la verificabilidad de regularidades. Desgraciadamente, como vimos, en el caso de las reglas sus afirmaciones acerca de "prácticas" pueden interpretarse superficialmente como tesis regularistas.

En segundo lugar, Wittgenstein da a entender, como la analogía kripkeana nos hace esperar, que la diferencia no se encuentra en el ámbito de las condiciones de afirmabilidad. De hecho, Wittgenstein parece inferir del argumento acerca del regreso de las justificaciones condensado en SC 245 (la proposición creída de que tengo dos manos es para mí una proposición sin fundamento) que (S) y $\left(S^{*}\right)$ tienen en esencia las mismas condiciones de afirmabilidad. Y el hecho de que Wittgenstein formule la pregunta relevante acerca de la idea de distinguibilidad en la forma de (P2'), y no la responda directamente afirmando la existencia de dos hechos diferentes descritos por $(S)$ y $\left(S^{*}\right)$, sugiere que presupone una concepción antifactualista de las atribuciones epistémicas.

En tercer lugar, Wittgenstein señala claramente que la diferencia está en lo que ocurre cuando lo que digo no me lo digo "a mí mismo", es decir, en lo que ocurre cuando se lo digo a otros. Y señala que la diferencia está en que otros están de acuerdo conmigo en cuanto a la aceptabilidad de la proposición no fundamentada pertinente; desde luego, dado que esto no sería diferencia alguna a menos que pudieran en principio discrepar, Wittgenstein da a entender que son estas dos circunstancias juntas las que distinguen (S) de $\left(\mathrm{S}^{*}\right)$ (y de $\left(\mathrm{S}^{* *}\right)$ ).

En cuarto lugar, el argumento de Wittgenstein en Sobre la certeza es un argumento completamente general ("¿A quién le dice alguien que sabe algo?"), no uno que trate de una clase específica de proposiciones o 
fundamentos epistémicos intuitivos (y mucho menos uno que trate acerca de una clase específica de regularidades en mi conducta de aceptar proposiciones). Esto apoya la idea kripkeana de que el argumento básico acerca de la noción de privacidad en las Investigaciones es general, y no tiene que ver exclusivamente con la clase específica de cosas supuestamente justificatorias conocidas como "definiciones ostensivas privadas".

Naturalmente, estas observaciones requieren un tratamiento más detallado que el que puedo ofrecer en este trabajo, tan extenso ya. Sin embargo, pienso que incluso esta presentación en esbozo crea dudas acerca de las lecturas predominantemente antikripkeanas de las Investigaciones y sugiere que una reconstrucción kripkeana puede ser más razonable y más wittgensteiniana de lo que comúnmente se piensa. En consecuencia, la repetida afirmación de que la concepción antifactualista expuesta por Kripke no puede siquiera apelar a un "argumento de autoridad" deviene mucho menos creíble.

\section{BIBLIOGRAFÍA}

Baker, G. y P. Hacker, 1984, Scepticism, Rules and Language, Blackwell, Oxford.

Boghossian, P., 1989, “The Rule-Following Considerations”, Mind, vol. 98, pp. 507549.

— 1990, "The Status of Content", Philosophical Review, vol. 99, pp. 157-184.

Burge, T., 1993, "Content Preservation", Philosophical Review, vol. 102, pp. 457488.

Kripke, S., 1982, Wittgenstein on Rules and Private Language, Harvard University Press, Cambridge, Mass.; versión en castellano: Wittgenstein: reglas y lenguaje privado, trad. A. Tomasini, Instituto de Investigaciones Filosóficas-UNAM, México, 1989.

Loar, B., 1985, "Review of Saul Kripke, Wittgenstein on Rules and Private Language", Noûs, vol. 19, pp. 273-280.

McGinn, C., 1984, Wittgenstein on Meaning, Blackwell, Oxford.

Soames, S., 1998a, "Facts, Truth-Conditions, and the Skeptical Solution to the RuleFollowing Paradox", Philosophical Perspectives, vol. 12, pp. 313-348.

— 1998b, "Skepticism about Meaning: Indeterminacy, Normativity, and the Rule-Following Paradox", Canadian Journal of Philosophy, vol. sup. 23, pp. 211249.

Stroud, B., 1996, "Mind, Meaning, and Practice", en H. Sluga (comp.), The Cambridge Companion to Wittgenstein, Cambridge University Press, Cambridge, pp. 296-319.

Wittgenstein, L., 1958 (IF), Philosophische Untersuchungen/Philosophical Investigations, 2a. ed., Macmillan, Nueva York; versión en castellano: Investigaciones filosóficas, trad. A. García Suárez y U. Moulines, Instituto de Investigaciones Filosóficas-UNAM, México, 1988.

—_, 1969 (SC), Über Gewißheit/On Certainty, Blackwell, Oxford. [Versión en castellano: Sobre la certeza, trad. J.L. Prades y V. Raga, Gedisa, Barcelona, 1988.] 
Wright, C., 1984, "Kripke's Account of the Argument against Private Language", Journal of Philosophy, vol. 81, pp. 759-778.

Zalabardo, J., 1997, "Kripke's Normativity Argument", Canadian Journal of Philosophy, vol. 27, pp. 467-488.

Recibido el 28 de febrero de 2005; aceptado el 28 de junio de 2005.

Diánoia, vol. L, no. 55 (noviembre 2005). 